\title{
Thermal Shock Analysis of Ceramic Multihundred Watt Spheres
}

V. J. Tennery

March 25, 1974

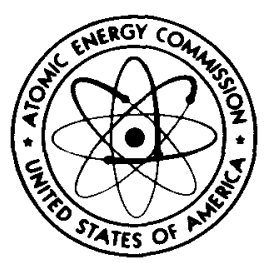

AEC Research and Development Report

Monsanto

\section{MOUND LABORATORY}

Miamisburg, Ohio

operated by

MONSANTO RESEARCH CORPORATION a subsidiary of Monsanto Company for the
U. S. ATOMIC ENERGY COMMISSION
U. S. Government Contract No. AT-33-1-GEN-53 


\section{DISCLAIMER}

This report was prepared as an account of work sponsored by an agency of the United States Government. Neither the United States Government nor any agency Thereof, nor any of their employees, makes any warranty, express or implied, or assumes any legal liability or responsibility for the accuracy, completeness, or usefulness of any information, apparatus, product, or process disclosed, or represents that its use would not infringe privately owned rights. Reference herein to any specific commercial product, process, or service by trade name, trademark, manufacturer, or otherwise does not necessarily constitute or imply its endorsement, recommendation, or favoring by the United States Government or any agency thereof. The views and opinions of authors expressed herein do not necessarily state or reflect those of the United States Government or any agency thereof. 


\section{DISCLAIMER}

Portions of this document may be illegible in electronic image products. Images are produced from the best available original document. 


\title{
Thermal Shock Analysis of Ceramic Multihundred Watt Spheres
}

\author{
V. J. Tennery \\ Issued: March 25, 1974
}

\section{NOTICE}

\begin{abstract}
This report was prepared as on account of work sponsored by the United States Government Neither the United States nor the United States Atoms Energy Commission, nur any of their employees, nor any of their contractors, subcontractors, or thesr employees, makes any warranty, express or implied, or assumes any legal liability or responsibility for the accuracy, completeness or usefulness of any information, apparatus, product or process disclosed, or represents that its use would not infringe privately owned rights
\end{abstract}

PRINTED IN THE UNITED STATES OF AMERICA Avalable from National Technical Information Service

U S Department of Commerce 5285 Port Royal Road

Springfield Virginio 2215

Price Printed Copy $\$ 400$ Microfiche $\$ 145$

\section{MONSANTO RESEARCH CORPORATION}

A Subsidiary of Monsanto Company

\section{MOUND LABORATORY}

Miamisburg, Ohio

45342

operated for

\section{UNITED STATES ATOMIC ENERGY COMMISSION}

U S Government Contract No AT-33-1-GEN-53 


\begin{abstract}
The thermal fracture resistance of plutonia Multihundred watt (MHW) fuel spheres was analyzed assuming boundary conditions of 1 ) constant heating or cooling rate for the sphere surface, 2) heating or cooling with a constant surface heat transfer coefficient at the sphere surface, and 3 ) heating or cooling the sphere surface solely by radiation. Thermal damage resistance (mechanical weakening) of MHW spheres was analyzed in terms of the fracture energy and crack system present in the fuel. Using avai1able property data for porous $\mathrm{PuO}_{2}$ between 400 and $1200^{\circ} \mathrm{C}$, and estimating other properties from available data for $\mathrm{UO}_{2}$ and $\mathrm{ThO}_{2}$, the thermal shock conditions that cause fracture of the fuel sphere were estimated. Experimental values for the tensile fracture strength and the elastic modulus of the fuel as functions of temperature are presently not available and estimates were made of these properties.
\end{abstract}




\section{INTRODUCTION}

The fuel form for the Multihundred Watt (MHW) generator consists of a solid sphere of ${ }^{2}{ }^{8} \mathrm{PuO}_{2}$ with a radius of approximately 1.46 in. and a density of about $85 \%$ of theoretical. These units are welded into a closefitting iridium sphere before being assembled into a spiral array of 24 spheres prior to mating with the generator.

Fracturing of the MHW fuel spheres prior to their encapsulation in the iridium shell would greatly complicate loading of the fuel sphere into its containment, because of the difficulty of handling the separate pieces, and the necessity of fitting these pieces together to form a sphere at the time of fueling and welding the iridium shell. The pure plutonium oxide (PPO) fuel is a brittle ceramic material and tends to fracture mechanically in tension, as this is the typical mechanical failure mode for a brittle solid. Thermally induced and mechanically applied stresses can originate in a fuel sphere. The former can arise during the hot press fabrication of the sphere, as well as during subsequent handling of the fabricated sphere. Due to the relatively high (approximately 0.38 W/g) internal energy generation rate of PPO fuel, relatively large thermal stresses can be easily generated in a sphere if the heat transfer to and from the sphere is changed abruptly by a significant amount. Mechanically applied stresses are controlled by appropriate design and control of the sphere-handling equipment used during fabrication and processing. Thermal$1 y$ induced stresses can be minimized by careful control of the sphere temperature and the surface heat transfer coefficient.

This report includes a discussion of the thermally induced stresses that are expected in a MHW fuel sphere and an analysis for determination of thermal conditions which may cause fracturing of the fuel sphere due to these thermal stresses. In particular, the analysis identifies the mechanical properties of the fuel which most affect thermal fracture resistance.

\section{THERMAL SHOCK RESISTANCE PARAMETERS}

The thermal shock fracture resistance of ceramic MHW spheres is a function of certain mechanical properties of the plutonia fuel, the heat transfer coefficient for the fuel sphere surface, the size of the sphere, and the stress fields induced in a solid sphere by thermal gradients. Due to the fact that plutonia is a brittle solid, ceramic MHW spheres fail primarily due to tensile or shear stresses rather than in compression. In this analysis, it is assumed that $\mathrm{PuO}_{2}$ has a lower tensile strength than shear strength. Since this is typical for brittle materials, 
the assumption seems reasonable, although there are no experimentally determined tensile and shear strengths for $\mathrm{PuO}_{2}$.

During heating from an initial temperature, $\mathrm{T}_{1}$, to a higher temperature, $\mathrm{T}_{2}$, the surface of a MHW sphere is in compression, whereas the center of the sphere is in tension. The effective neutral axis moves along the radius as a complex function of several variables which will be discussed in detail later. Thermal fracturing of a sphere during heating occurs due to tensile failure in the sphere center, and results in the formation of pyramidal-like fracture segments. Cooling of a sphere from a given temperature, $\mathrm{T}_{1}$, to a lower temperature, $\mathrm{T}_{2}$, results in tensile stresses in the surface and compressive stresses in the center. Mechanical failure of a sphere during cooling results in tensile failure in regions of the surface.

The surface and center stresses in a sphere that arise due to a symmetrical temperature distribution in this shape are given by: ${ }^{1}$

$$
\begin{array}{lc} 
& \text { Surface } \\
\sigma_{\mathbf{t}}=\frac{E \alpha}{(1-\mu)}\left(t_{\mathbf{a}}-t_{\mathbf{s}}\right) & \sigma_{\mathbf{t}}=\sigma_{\mathbf{r}}=\frac{2 \mathrm{E} \alpha}{3(1-\mu)}\left(t_{\mathbf{a}}-t_{c}\right) \\
\sigma_{\mathbf{r}}=0 &
\end{array}
$$

where,

$$
\begin{aligned}
\sigma_{\mathbf{t}} & =\text { tangential stress component } \\
\sigma_{\mathbf{r}} & =\text { radial stress component } \\
\mathrm{E} & =\text { Young's modulus for the material } \\
\mu & =\text { Poisson's ratio for the material } \\
\alpha & =\text { thermal expansion coefficient for the material } \\
t_{\mathbf{a}} & =\text { space-averaged temperature for the sphere } \\
t_{\mathbf{s}} & =\text { surface temperature } \\
t_{\mathbf{c}} & =\text { center temperature. }
\end{aligned}
$$

For a given $\Delta \mathrm{T}$ in a sphere under these conditions, the ratio of the center stress to the surface stress is $2 / 3$. Therefore, a given sphere is more sensitive to fracture during cooling than it is during heating due to this stress ratio. In some cases, the spatial temperature distribution in an object is not symmetrical. This would be the case, for example, when a sphere at temperature $\mathrm{T}_{1}$ is suddenly subjected to a new environment at $\mathrm{T}_{2}$ and the heat transfer coefficient, $h$, is very large.

Various thermal stress resistance parameters for brittle solids have been investigated. ${ }^{2,3,4,5}$ Basically there are five of these parameters, and the specific one which applies for a particular material in a particular thermal stress environment must be established experimentally. These parameters are related to the material properties as shown:

$$
\begin{aligned}
& R=\frac{S_{t}(1-\mu)}{E \alpha} \\
& R^{\prime}=R(k)
\end{aligned}
$$




$$
\begin{aligned}
& R^{\prime}=a R \\
& R^{\prime \prime}=\frac{E}{S_{t}^{2}(1-\mu)} \\
& R^{\prime}{ }^{\prime \prime}=R^{\prime \prime \prime}(\gamma)
\end{aligned}
$$

where,

$$
\begin{aligned}
S_{t} & =\text { fracture tensile strength } \\
k & =\text { thermal conductivity of the solid } \\
a & =\text { thermal diffusivity of the solid } \\
\gamma & =\text { effective fracture energy of the solid }
\end{aligned}
$$

and the other constants are defined as before.

The thermal resistance factors, $R, R^{\prime}$, and $R^{\prime \prime}$, are primarily related to the fracture resistance, while $R^{\prime \prime} '$ and $R^{\prime \prime} '$ ' are primarily related to the thermal damage resistance. Thermal damage resistance refers to the maximum temperature differential that causes a significant degradation of the mechanical properties of an object made of brittle material, while thermal fracture resistance is the maximum temperature differential that causes catastrophic fracturing of the object.

\section{$\underline{\mathrm{R}}$ Parameter}

The $R$ parameter is related to a temperature change in the surroundings leading to thermal fracture of a specific object by an expression of the form:

$$
\Delta t_{s}=R \cdot S
$$

where,

$$
\begin{aligned}
\Delta t_{t}= & \text { temperature change necessary to cause fracture of a } \\
& \text { particular shape } \\
R= & \text { thermal fracture parameter } \\
S= & \text { shape factor for the particular shape. }
\end{aligned}
$$

The shape factor contains the geometric aspects of the particular shape under consideration. Equation 6 is applicable when the surface heat transfer coefficient, $h$, is essentially infinite.

\section{$\underline{R^{\prime} \text { Parameter }}$}

The $R^{\prime}$ parameter is related to the maximum thermal flux which can induce fracture in a specific object. It is represented by an expression of the form:

$$
\mathrm{q}_{\mathbf{m a x}}=\mathrm{R}^{\prime} \cdot \mathrm{S}^{\prime}
$$

where,

$$
\mathrm{q}_{\max }=\underset{\text { maximum permissible thermal flux that will not cause }}{\operatorname{macture}}
$$




$$
\begin{aligned}
& R^{\prime}=\text { second thermal stress resistance parameter } \\
& S^{\prime}=\text { shape factor for the particular shape }
\end{aligned}
$$

and the temperature difference between the object and its surroundings that can induce fracture is:

$$
\Delta t_{f}=R^{\prime} \cdot S \cdot \frac{1}{h}
$$

where,

$$
\mathrm{h}=\text { surface heat transfer coefficient applicable to the }
$$
shape under the specified conditions.

The factor $S^{\prime}$ is different from $S$ for the same shape. Values for $S$ and $S^{\prime}$ have been calculated for a limited number of simple shapes.

R'' Parameter

The $R^{\prime \prime}$ parameter is related to the thermal fracture resistance of a shape that has an imposed constant rate of change of surface temperature. The surface heat transfer coefficient changes continuously with temperature in this case. The maximum rate of temperature change $\left(Q_{\max }\right)$ which can be tolerated without fracture of a given object under these conditions is given by:

$$
Q_{\max }=R^{\prime \prime} \cdot S^{\prime \prime}
$$

where $S^{\prime \prime}$ is different from the $S$ and $S^{\prime}$ factors discussed previously. Values for S'' are known for only a few shapes. Expressions relating thermal stresses and surface heating rates are required for determining $Q_{m a x}$ for a particular material and shape. Stresses induced in a plane slab by a constant rate of temperature change, $Q$, are given by: ${ }^{1}$

$$
\sigma_{s}=\frac{E \alpha}{(1-\mu)} \cdot \frac{Q}{3} \cdot \frac{r_{m}{ }^{2}}{a}
$$

and

$$
\sigma_{c}=\frac{E \alpha}{(1-\mu)} \cdot \frac{Q}{6} \cdot \frac{r_{m}{ }^{2}}{a}
$$

where,

$$
\begin{aligned}
\sigma_{s} & =\text { surface stress } \\
\sigma_{c} & =\text { center stress } \\
Q & =\text { heating or cooling rate of the slab surface } \\
r_{m} & =\text { half thickness of the slab }
\end{aligned}
$$

and the other constants are defined as previously.

Similarly, the difference between surface temperature, $t_{s}$, and center temperature, $\mathbf{t}_{c}$, varies for various shapes cooled at a constant rate as shown in Table 1.1 
Table 1

CENTER-SURFACE TEMPERATURE DIFFERENTIAL OF VARIOUS SHAPES AT CONSTANT COOLING

$\begin{array}{ll}\text { Shape } & \frac{t_{c}-t_{s}}{0.50 \quad \mathrm{Qr}_{\mathrm{m}}{ }^{2} / \mathrm{a}} \\ \text { Infinite plate, half thickness }=\mathrm{r}_{\mathrm{m}} & 0.25 " \mathrm{"} \\ \text { Infinite cylinder, radius }=\mathrm{r}_{\mathrm{m}} & 0.201 " \\ \text { Cylinder, half length }=\mathrm{r}_{\mathrm{m}} & 0.221 " \\ \text { Cube, half thickness }=\mathrm{r}_{\mathrm{m}} & \end{array}$

Therefore, for the case of a sphere, the maximum acceptable heating and cooling rates that do not induce fracture can be estimated by assuming that a sphere is an approximation of a cube and that the same expressions apply to heating and cooling conditions. Since Table 1 indicates that the quantity $\left(t_{c}-t_{s}\right)$ is not strongly dependent upon the geometric shape of the object, the assumption that $t_{c}-t_{s} \simeq Q r_{m}{ }^{2} / 5 a$ appears to be reasonable for the case of a sphere.

Using this assumption for the shape, and substituting into the expressions given earlier for surface and center stresses in a sphere, the relationship between stress and heating or cooling rate can be derived by making the following additional assumption about temperature distribution in the sphere. If the average temperature is assumed equal to the arithmetic average of the center and surface temperatures, the thermal stress can be easily calculated in terms of these two temperatures. For the surface stress in a sphere this expression is:

$$
\sigma_{s} \simeq \frac{E \alpha}{(1-\mu)} \cdot \frac{Q}{10} \cdot \frac{r_{m}^{2}}{a}
$$

while the center stress is given by:

$$
\sigma_{0} \simeq \frac{E \alpha}{(1-\mu)} \cdot \frac{Q}{15} \cdot \frac{r_{m}^{2}}{a}
$$

If the critical stress for sphere fracture is the tensile stress, Equation 12 can be rearranged according to Equation 9 as:

$$
Q_{\max }=\frac{a S_{t}(1-\mu)}{E \alpha} \cdot \frac{10}{r_{m}^{2}}
$$

where this expression is valid for the surface, and therefore applies to cooling conditions.

Likewise, Equation 13 can be rearranged as:

$$
Q_{\text {max }}=\frac{a S_{t}(1-\mu)}{E \alpha} \cdot \frac{15}{r_{m}^{2}}
$$

where this expression is valid for the center, and therefore applies to a sphere being heated. 
A more conservative assumption that can be applied in these derivations is that for cooling, the center temperature is approximately equal to the average temperature. With this assumption, Equation 14 becomes:

$$
Q_{\max }=\frac{a S_{t}(1-\mu)}{E_{\alpha}} \cdot \frac{5}{r_{m}^{2}}
$$

Assuming that for heating, the surface temperature is approximately equal to the average temperature, Equation 15 becomes:

$$
Q_{\max } \simeq \frac{\mathrm{aS}_{\mathrm{t}}(1-\mu)}{\mathrm{E} \alpha} \cdot \frac{7}{\mathrm{r}_{\mathrm{m}}{ }^{2}}
$$

The cooling rate and the heating rate given by Equations $14 \mathrm{a}$ and $15 \mathrm{a}$, respectively, are lower, by essentially a factor of two, than those given by Equations 14 and 15 .

Due to the more conservative nature of Equations $14 \mathrm{a}$ and $15 \mathrm{a}$, these expressions are used in the following discussion to estimate maximum acceptable heating and cooling rates for MHW spheres when the surface temperature is varied at a linear time rate. Within the limits of this approximation, a given sphere can be safely heated at a somewhat faster rate than the maximum acceptable cooling rate before fracture failure occurs.

Equations 14, 14a, 15, and 15a have the essential form of Equation 9; $S^{\prime \prime}$ in this case is different for heating and cooling because of the properties of the stress field in a sphere. The maximum acceptable heating and cooling rates are inversely proportional to the square of the sphere radius; thus, the smaller the sphere, the higher the heating and cooling rates that can be used without fracturing it. Equations 14, 14a, 15 , and $15 a$ are reasonably valid only under the boundary condition that the surface temperature of the sphere is changed at a linear rate with time. These expressions will be evaluated shortly along with others for the case of $\mathrm{PuO}_{2}$. It should be noted that these models do not include the internal heat generation characteristic of ${ }^{238} \mathrm{PuO}_{2}$, and this affects the results to some extent. The heat generation characteristic of ${ }^{238} \mathrm{PuO}_{2}$ results in the generation of significant thermal stresses, for the case where no external heat is provided, if the fuel sphere does not have suitable thermal insulation from its surroundings. When external heat is provided to the sphere at a rate that is significantly higher than the self-heat generation rate, the relative magnitude of the thermal gradients and resultant stresses due to self-heat is of less importance. Recent experimental measurements of the radial temperature gradient in a ${ }^{238} \mathrm{PuO}_{2}$ MHW sphere at LASL* have shown temperature differences between surface and core of approximate $1 y 250^{\circ} \mathrm{C}$, with a core temperature of approximately $650^{\circ} \mathrm{C}$, when self-heat is the primary energy source.

\section{Thermal Damage Resistance Parameters}

The thermal damage parameters R' ' and R''' will be discussed later in this report as they apply to PPO spheres. These parameters evaluate the thermal shock conditions which cause significant microcracking and degradation of mechanical strength, but not necessarily fracture, in the material. Since the tensile breaking strength is a parameter in all of the expressions involving $R, R^{\prime}$, and $R^{\prime}$ ', a significant decrease of $S_{t}$

*T. K. Keenan and R. Kent, located at CMB-11, LASL . 
obviously results in a change in the thermal shock fracture resistance of PPO spheres. Since $R, R^{\prime}$, and $R^{\prime}$ ' are concerned with the thermal shock conditions which lead to physical fracturing of a given shape, these will be analyzed first in regard to MHW spheres.

THERMAL SHOCK IN A SPHERE WITH A CONSTANT BIOT'S MODULUS

The thermal stress problem in a sphere has been analyzed by employing Biot's modulus $(\beta)$, a dimensionless surface heat transfer coefficient, to derive an expression relating thermal shock fracture in a sphere to (1) the material properties, $(2){ }_{6,7}^{B}$ and (3) the temperature change in the
vicinity of the sphere's surface.

The mathematical solution to this problem changes as a function of $\beta$, but the values of $\beta$ that would probably be applicable for heating and cooling MHW spheres during processing would no doubt be in the range 0.1 to 10 , as this range includes the expected range of the heat transfer coefficient, h. Within this range of values, the following is applicable to a sphere:

$$
\Delta T=\frac{S_{t}(1-\mu)}{E \alpha} \frac{5(\beta+2)}{2 \beta} \quad(0.1 \leq \beta \leq 10)
$$

where,

$$
\begin{aligned}
\Delta \mathrm{T}= & \text { temperature difference between the sphere and its } \\
& \text { surroundings which causes fracture } \\
\beta= & \text { Biot's modulus } \frac{\text { rh }}{K}
\end{aligned}
$$

and,

$$
\begin{aligned}
\mathrm{r}= & \text { sphere radius } \\
\mathrm{h}= & \text { surface heat transfer coefficient at the sphere } \\
& \text { surface } \\
\mathrm{K}= & \text { thermal conductivity of the sphere material. }
\end{aligned}
$$

This expression can be rearranged to the approximate form of Equation 8 as :

$$
\Delta \mathrm{T}=\frac{5 \mathrm{~S}_{\mathrm{t}}(1-\mu)}{2 \mathrm{E} \alpha}+\frac{5 \kappa S_{\mathrm{t}}(1-\mu)}{\mathrm{rhE} \alpha}
$$

The solution for the sphere in this case does not result in a readily identifiable $R^{\prime}$ or $R^{\prime \prime}$ parameter, but consists of two parts:

$$
\Delta T=\frac{S_{t}(1-\mu)}{\alpha E} S_{1}+\frac{k S_{t}(1-\mu)}{\alpha E} S_{2}
$$

or, $\Delta \mathrm{T}=\mathrm{RS}_{1}+\mathrm{R}^{\prime} \mathrm{S}_{2}$

where,

$$
\begin{aligned}
& R \text { and } R^{\prime} \text { are defined as in Equations } 1 \text { and } 2 \\
& S_{1}=5 / 2 \\
& S_{2}=5 / \mathrm{rh} .
\end{aligned}
$$


$S_{1}$ and $S_{2}$ in this case are shape factors, and $S_{2}$ also contains the surface heat transfer coefficient. This model for the sphere is applicable for the case of $\beta=$ constant during the application of the thermal shock, and the fracture resistance is a function of two thermal stress resistance parameters. The solution for a sphere also provides an expression for the time required to induce fracture in a solid sphere as a result of changing it abruptly from a region of equilibrium temperature $\mathrm{T}_{1}$ to a region of temperature $\mathrm{T}_{2}$ when $\beta=$ constant. In many conceivable situations, $\beta$ is not a constant and in these cases, the results computed using Equation 16 may be used as reasonable approximations when the variation of $\beta$ during the thermal shock is not too large. The important case in which cooling of the sphere is by radiation alone has been solved approximately ${ }^{8}$ and will be discussed in the next section.

For the case in which $\beta=$ constant, the surface heat transfer coefficient and material thermal conductivities are constant. Thus, the time to maximum stress, $\theta^{\prime}$, after the temperature surrounding the sphere changes from $\mathrm{T}_{1}$ to $\mathrm{T}_{2}$, is given by:

$$
0^{\prime}=\frac{\theta r^{2}}{a}
$$

where,

$$
\begin{aligned}
& \theta=\text { nondimensional time } \\
& r=\text { sphere radius } \\
& a=\text { thermal diffusivity of sphere material. }
\end{aligned}
$$

The quantity $\theta^{\prime}$ is also the approximate time required for fracture if the $\Delta T$ is sufficient to cause a thermal stress equal to, or greater than, the tensile fracture stress for the sphere material. As shown in Figure 1 , the factor called nondimensional time, $\theta$, varies as a function of $\beta$ and radial position in the sphere. ${ }^{6}$

\section{THERMAL SHOCK OF A SPHERE BY RADIATION HEATING AND COOLING}

Thermal shock by radiation heating of various shapes, especially a sphere, has been investigated, ${ }^{8}$ including a reanalysis of the earlier study employing constant $\beta .{ }^{6}$ The basic problem encountered in the analysis of a sphere being heated or cooled by radiation alone is the definition of the boundary conditions, since the heat transfer coefficient varies continuously with the temperature of the sphere surface; and the heat transfer to the sphere changes as a function of the sphere surface temperature, the temperature of its surroundings, and the emissivities of both. A sphere cooled or heated solely by radiation transfer may be a close approximation to a MHW sphere in a refractory metal furnace under vacuum.

The principal boundary conditions which apply to the radiation conditions appropriate to the solution for a sphere in this analysis are that (1) during heating, the sphere is reradiating no energy back to its environment; and (2) during cooling, the environment surrounding the sphere reradiates no energy to the sphere. If a refractory metal furnace containing a sphere at $1500^{\circ} \mathrm{C}$ in vacuum is abruptly switched off, it will no doubt radiate some thermal energy back to the sphere from the heating 


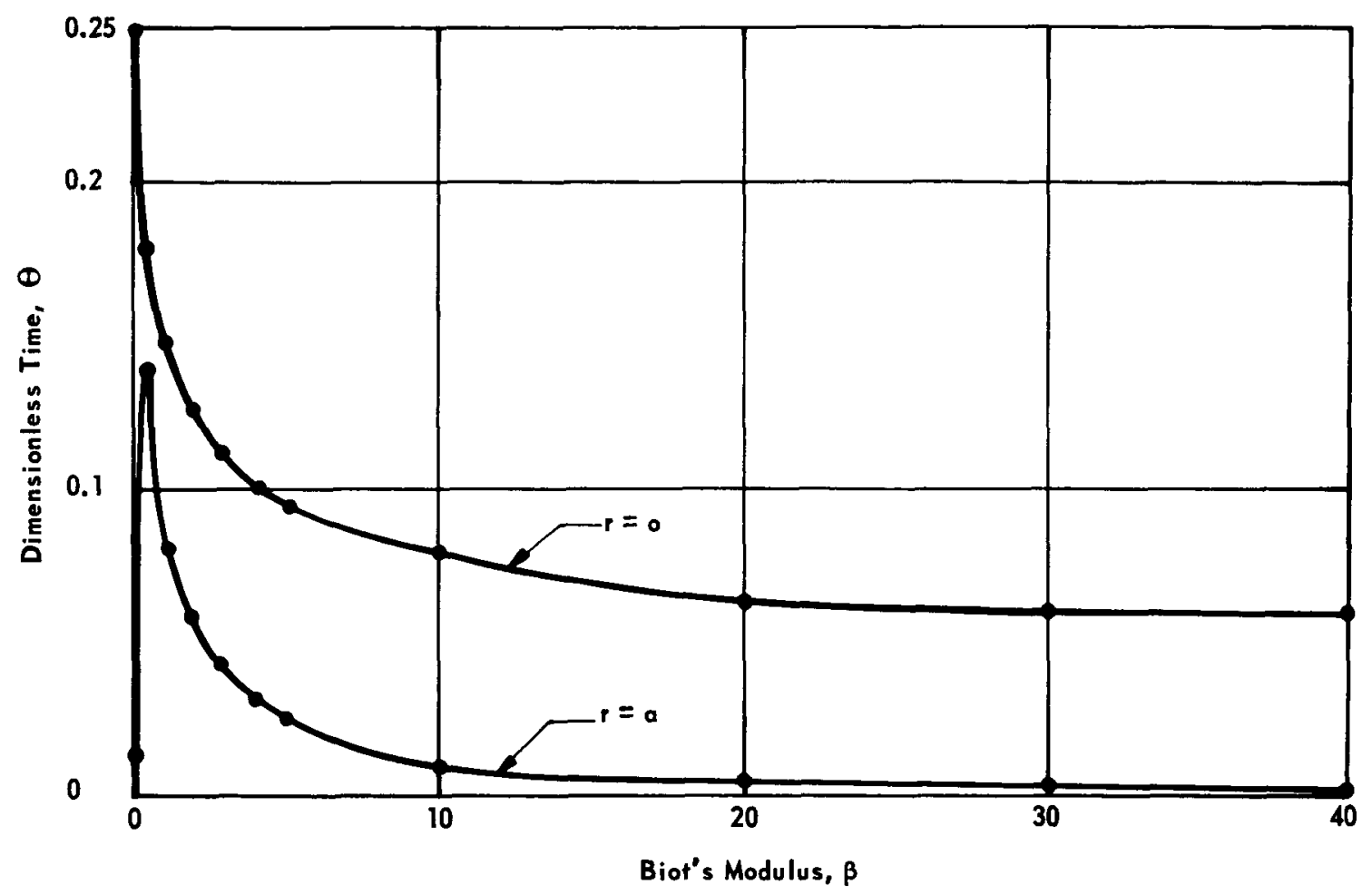

FIGURE 1 - Biot's Modulus for surface and center of a sphere with radius (r) of $a$.

element, inner shield, and pedestal structure. Calculations based upon this model will therefore be "worst case" conditions as far as radiation thermal shock of spheres is concerned, since reradiation from, or to, the sphere tends to reduce the severity of the thermal shock.

Therma1 Shock Fracture Resistance of a Sphere

In heating a sphere by radiation transfer only, the applicable assumption is that the initial sphere surface temperature, $T_{1}$, is very low relative to the enclosure temperature, $\mathrm{T}_{2}$, in which the sphere is rapidly placed. Under these conditions, the thermal flux is about $95 \%$ of that which would occur if $\mathrm{T}_{1}=0^{\circ} \mathrm{K}$ when $\mathrm{T}_{1} / \mathrm{T}_{2} \leq 0.475$. For this condition, as $\mathrm{T}_{1}$ increases toward $\mathrm{T}_{2}$ but the ratio $\mathrm{T}_{1} / \mathrm{T}_{2} \leq 0.475$, the thermal $\mathrm{flux}$ delivered to the sphere is essentially constant and the thermal stress equations can be solved. Under this condition, a sphere has maximum tensile stress at its center. Equating the maximum thermal stress to the tensile stress gives:

$$
q_{\max }=\frac{5 S_{t}(1-\mu) k}{r \alpha E}
$$

where,

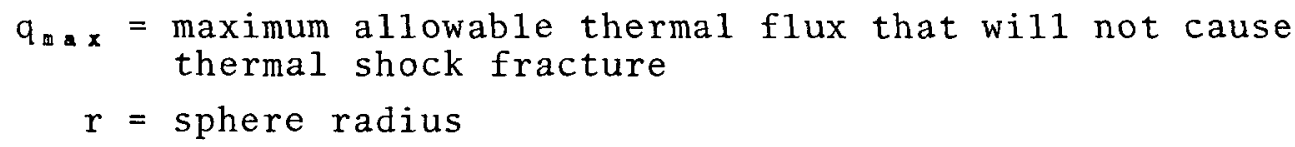

and other constants are defined as previously. 
Energy transfer by radiation occurs according to:

$$
\mathrm{q}_{\mathrm{max}}=\sigma \varepsilon\left(\mathrm{T}_{\mathrm{max}}{ }^{4}-\mathrm{T}_{1}{ }^{4}\right)
$$

where,

$$
\begin{aligned}
& \sigma=\text { Stefan-Bo1tzmann constant }=1.37 \times 10^{-12} \\
& \mathrm{cal} / \mathrm{deg}^{4}-\mathrm{cm}^{2}-\mathrm{sec} \\
& \varepsilon=\text { emissivity or absorptivity of surface } \\
& \mathrm{T}_{\mathrm{nax}}=\text { maximum radiation temperature to which body can be } \\
& \text { subjected without thermal shock fracture } \\
& \mathrm{T}_{1}=\text { initial sphere surface temperature. }
\end{aligned}
$$

$$
q_{\max }=\sigma \varepsilon \mathrm{T}_{\max }{ }^{4}
$$

Substituting this into Equation 20 gives $\mathrm{T}_{\max }$ in ${ }^{\circ} \mathrm{K}$ :

$$
\mathrm{T}_{\max }=\left[\frac{5}{\sigma r}\right]^{\frac{1}{4}}\left[\frac{\mathrm{S}_{t}(1-\mu) \kappa}{\alpha \mathrm{E} \varepsilon}\right]^{\frac{1}{4}}
$$

The analysis for cooling a sphere is complicated by the difficulty of knowing the effective emissivity of the enclosure. Assuming this is zero will give a worst case value for $T_{\max }$ for a sphere during cooling. In this case, for the maximum allowable radiation condition, the surface heat transfer coefficient, $h$, is assumed to vary as: ${ }^{8}$

$$
\mathrm{h}=4 \sigma \varepsilon \mathrm{T}_{\max }{ }^{3}
$$

Using the following approximation of Equation 16:

$$
\Delta \mathrm{T}_{\text {max }}=\frac{5 S_{t}(1-\mu) \kappa}{\alpha \operatorname{Erh}}
$$

the maximum allowable radiation temperature difference to which a sphere can be subjected upon cooling without fracture is given by an expression identical to Equation 23. This expression then allows an evaluation of the sensitivity of a MHW sphere to thermal fracture by radiation transfer, as compared to conditions where $\beta$ is assumed known and constant as in Equation 16, or where the surface temperature varies linearly with temperature as in Equations 14, 14a, 15, and 15a.

Therma1 Stress Damage Resistance of a Sphere

The remaining type of thermal shock damage to which MHW spheres may be subjected involves thermal shock in which thermal stress cracking is induced, but in which the thermal stresses are not sufficient to cause the sphere to fail catastrophically. A MHW sphere is obviously of little value if it does not maintain its shape integrity. However, thermal stress damage can be induced in a brittle solid in which cracking is initiated by thermal shock, but the cracks become arrested before the sphere breaks into pieces. A theory advanced for the analysis and interpretation of the thermal shock damage resistance of brittle solids ${ }^{3,4}$ is applied here to MHW spheres. The basic concept of this theory is that the driving force for crack propagation in a material such as ceramic 
$\mathrm{PuO}_{2.00}$ is the elastic energy stored in the solid at the initiation of fracture. This energy is dissipated during fracture by the energy requirements provided by the "effective surface energy", required to produce newly formed crack surfaces in the solid.

For a sphere subjected to thermal shock during heating, the total elastic energy, $W$, contained in the sphere at the moment that the maximum therma 1 stress attains the value of the tensile stress is given by:

$$
W=\frac{4 \pi r^{3} S_{t}^{2}(1-\mu)}{7 E}=\frac{3 S_{t}^{2}(1-\mu) V}{7 E}
$$

where,

$$
\begin{aligned}
r & =\text { sphere radius } \\
S_{t} & =\text { tensile strength of the brittle solid } \\
\mu & =\text { Poisson's ratio for the material } \\
E & =\text { Young's modulus of elasticity } \\
V & =\text { sphere volume. }
\end{aligned}
$$

At fracture all of the elastic energy is assumed to be transformed into effective surface energy; and the body, or its component parts, are assumed to be stress-free when the cracks are arrested or the body has disintegrated.

By equating the total surface energy required for propagation of cracks to the elastic energy stored at fracture as in Equation 26, the mean area over which $\mathrm{N}$ number of cracks can propagate in a sphere is given by:

$$
A=\frac{2 \pi S_{t}^{2}(1-\mu) r^{3}}{7 N E \gamma_{t: 1}}
$$

where,

$$
\gamma_{\text {ors }}=\text { effective surface energy for crack formation. }
$$

If the calculated area, A, for a given spherical sample is greater than the cross-sectional area of the sphere $\left(\pi r^{2}\right)$, the cracks completely traverse the piece and result in a complete failure, which can be quite explosive. If $A$ is smaller than the geometric cross-sectional area of the sphere, excess energy is not available and the fracture process is arrested and the sphere remains intact after the shock.

The relative degree of damage is directly proportional to the area over which the cracks propagate, so minimizing A results in maximum thermal damage resistance. The parameters $R^{\prime \prime}$ ' and $R^{\prime \prime}$ '' given in Equations 4 and 5 come from this analysis. R' ' can be used to compare materials with similar crack propagation properties, i.e., with the $\gamma_{\text {ef }}$ approximately equal. R'' can be used to compare the degree of thermal stress damage of materials with widely different $\gamma_{e s}$, such as brittle and ductile materials.

Examination of Equations 4, 5, and 27 shows that the thermal stress damage resistance of the brittle ceramic fuel can be increased by (1) designing the fuel so that it has a low tensile fracture strength, (2) ensuring that the fuel has a large number of cracks, $N$, in which to dissipate 
the thermal elastic energy, or (3) selecting a solid fuel system which has a large effective fracture energy, $\gamma$. The requirement of a low strength to provide thermal stress damage resistance is in opposition to the high strength requirement for thermal shock fracture resistance. These two properties can, therefore, usually not be provided by a single material. One which exhibits high resistance to thermal shock fracturing is often susceptible to thermal stress damage, usually characterized by a precipitous decrease in fracture strength once a critical $\Delta \mathrm{T}$ of thermal shock is exceeded. A large number of crack initiators can be provided by ensuring a high porosity in the ceramic, as well as by having a largegrained microstructure. Pores and large grains provide numerous microflaws which, upon application of a tensile stress, are the source of a large number of cracks, thus causing $N$ to be large.

For a sphere, an optimum strength can be calculated which provides a maximum strength after thermal shock. This is given by:

$$
S_{t}^{*}=\frac{1}{2}\left[\frac{7 N E Y \in f t}{2(1-\mu) r}\right]^{1 / 2}
$$

where,

$$
\begin{aligned}
\mathrm{S}_{\mathrm{t}}^{*} & =\text { strength of solid before thermal shock } \\
\mathrm{N}= & \text { number of cracks initiated in the solid } \\
& \text { during thermal shock } \\
\mathrm{r} & =\text { sphere radius } \\
\gamma_{0 \mathrm{f}}= & \text { effective surface energy for crack formation } \\
\mathrm{E} & =\text { Young's modulus of elasticity. }
\end{aligned}
$$

This expression can be used to estimate the strength of the sphere material which provides the maximum thermal stress damage resistance.

This approach to thermal damage analysis has been extended to define the critical temperature difference for a brittle solid which results in a dramatic reduction of strength. ${ }^{4}$. The thermal damage resistance of the solid according to this concept is related to several of the material constants discussed in the previous derivations as we 11 as the surface fracture energy and the length of the initial Griffith microcracks assumed present in all brittle solids. When the temperature difference impressed on the solid reaches a critical value, $\Delta \mathrm{T}_{c}$, crack propagation is initiated. The result of this process depends upon various properties of the solid. Thermal shock conditions that are not severe enough to cause catastrophic failure, will induce thermal cracking to propagate within the body until arrested by relief of the stress. The result of this process is either a dramatic weakening of the solid or a gradual decrease in strength of the solid. Solids, such as ceramic $\mathrm{Al}_{2} \mathrm{O}_{3}$, which have relatively high initial strength, experience an abrupt loss of strength at a critical shock temperature difference, $\Delta \mathrm{T}_{c}$. An initially weak solid undergoing thermal shock propagates cracks by a relatively stable process and its strength gradually decreases as a function of increasing thermal shock severity. These two different behaviors are illustrated in Figure 2 .

Alumina has been shown to behave as in Figure 2 (a) when thermal shocked in the form of cylindrical rods. After sustaining thermal shock damage when $\Delta \mathrm{T} \geq \Delta \mathrm{T}_{\mathrm{c}}$, the strength remains independent of $\Delta \mathrm{T}$ until a second critical shock temperature, $\Delta \mathrm{T}_{\mathrm{c}}^{\prime}$, is achieved. Insulating firebricks 


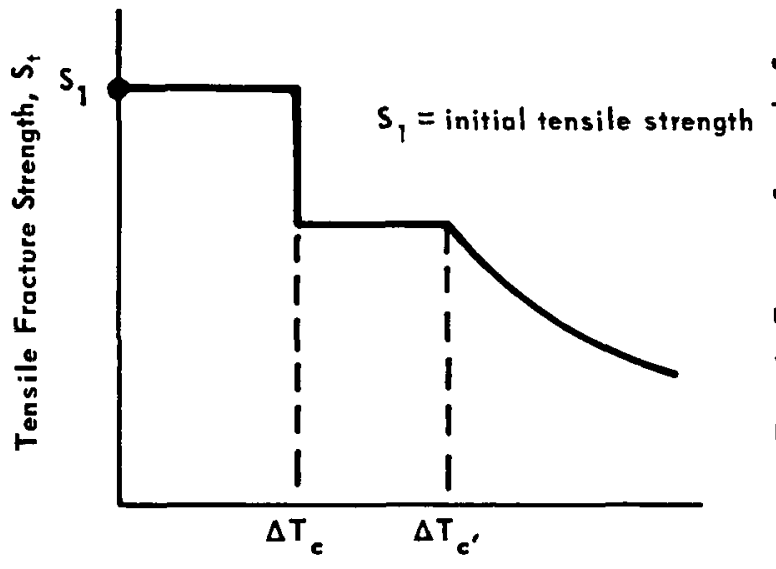

Temperature Difference, $\Delta T \rightarrow$

(a) High-Strength Brittle Solid

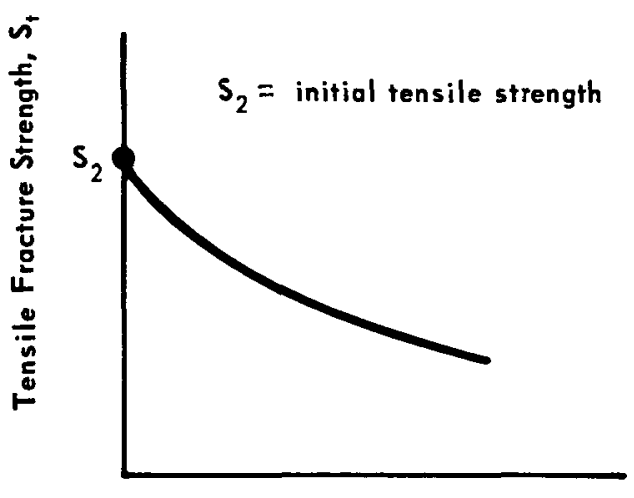

Temperature Difference, $\Delta T+$

(b) Low-Strength Brittle Solid

FIGURE 2 - Effect of thermal shock on initially high-and low-strength brittle solids.

behave very similarly to Figure 2 (b). No information could be found to indicate whether porous $\mathrm{PuO}_{2}$ behaves as in (a) or (b) when thermally shocked. If the crack density in PPO material is relatively low and the material behaves as in (b), thermal shock could lead to crack growth in the MHW sphere that would result in gradual sphere weakening. If PPO fuel behaves as in (a), the application of a thermal shock greater than $\Delta \mathrm{T}_{\mathrm{e}}$ results in a sharp decrease in strength, and the sphere, at the same time, becomes much more prone to thermal shock fracture.

The analysis of crack initiation and propagation in brittle ceramics has been analyzed for (1) the case of a ceramic body with penny-shaped cracks and a uniform triaxial stress, ${ }^{4}$ and (2) the case of a rigidly constrained, uniformly cooled, thin, flat plate with a uniform distribution of microcracks.9 The results from these calculations are qualitatively similar and relate the initial crack length in the solid to the temperature difference necessary to cause either crack propagation and catastrophic failure, or only an increase in the crack length.

To illustrate, the case of triaxial stress will be discussed in some detail. The thermally induced stress in the solid, $S$, due to cooling by a temperature increment, $\Delta \mathrm{T}$, is given by:

$$
S=\alpha E \Delta T /(1-2 \mu)
$$

where the constants are defined as previously. No stress relaxation mechanism, such as dislocation motion or viscous flow, is assumed. Crack propagation is assumed to occur by simultaneous propagation of $\mathrm{N}$ number of cracks per unit volume. All cracks are assumed to be of uniform size 
and to propagate radially. No interactions between stress fields of neighboring cracks are assumed.

For the assumed stress and crack configuration, the total energy, $W_{t}$, per unit volume at any instant is the sum of the elastic energy in the solid plus the fracture energy associated with the cracks. Following Griffith's treatment, the cracks are unstable whenever:

$$
\frac{d W_{t}}{d L} \leq 0
$$

where,

$$
\mathrm{L}=\text { crack length. }
$$

For both of the stress states for which solutions are available, an expression can be derived which relates the critical temperature change, $\Delta \mathrm{T}_{\mathrm{c}}$, that produces crack instability to the initial crack length present in the solid. In the case of triaxial stress, rigidly constrained external surfaces, or penny-shaped cracks, this expression is:

$$
\Delta \mathrm{T}_{c}=\left[\frac{\pi \gamma(1-2 \mu)^{2}}{2 \mathrm{E}_{0} \alpha 2(1-\mu 2)}\right]^{1 / 2}\left[1+\frac{16\left(1-\mu^{2}\right) \mathrm{NL}^{3}}{9(1-2 \mu)}\right][\mathrm{L}]^{-1 / 2}
$$

where,

$$
\begin{aligned}
\gamma= & \text { surface fracture energy of the solid } \\
L= & \text { crack length } \\
E_{0}= & \text { Young's modulus of crack-free material } \\
\mathrm{N}= & \text { initial number of cracks present in solid per } \\
& \text { unit volume. }
\end{aligned}
$$

For the case of a rigidly constrained flat plate, the equivalent expression is:

$$
\Delta \mathrm{T}_{\mathrm{c}}=\left[\frac{2 \gamma}{\pi \mathrm{L} \alpha^{2} \mathrm{E}_{\circ}}\right]^{1 / 2}\left[1+2 \pi N \mathrm{~L}^{2}\right]
$$

Both Equations 31 and 32 show very similar dependencies of $\Delta \mathrm{T}_{\mathrm{c}}$ upon $\mathrm{L}$. Thus, it appears a reasonable assumption that the functional behavior shown in Figure 3 for the case of triaxial stress will be reasonably genera1. Consequent1y, the stress state in a PPO sphere during heating and cooling is probably such that the dependence of $\Delta \mathrm{T}_{c}$ upon initial crack 1ength in the fuel can be reasonably approximated by a diagram similar to Figure 3. For short initial cracks, the critical temperature difference required for crack propagation is independent of the crack density but does depend upon the fuel properties: $\gamma, E, \alpha, \mu$, and $L$.

For a ceramic fuel fabricated with an initial crack length, L, the critical temperature difference which causes crack propagation decreases, as the crack length increases from near $10 \mu \mathrm{m}$ to about $500 \mu \mathrm{m}$. Fuel containing a relatively large crack density becomes more resistant to crack propagation at longer crack lengths than does fuel containing only a few cracks. This occurs because the larger number of cracks tends to limit the thermal strain developed in a specific region of the fuel during thermal stress. 


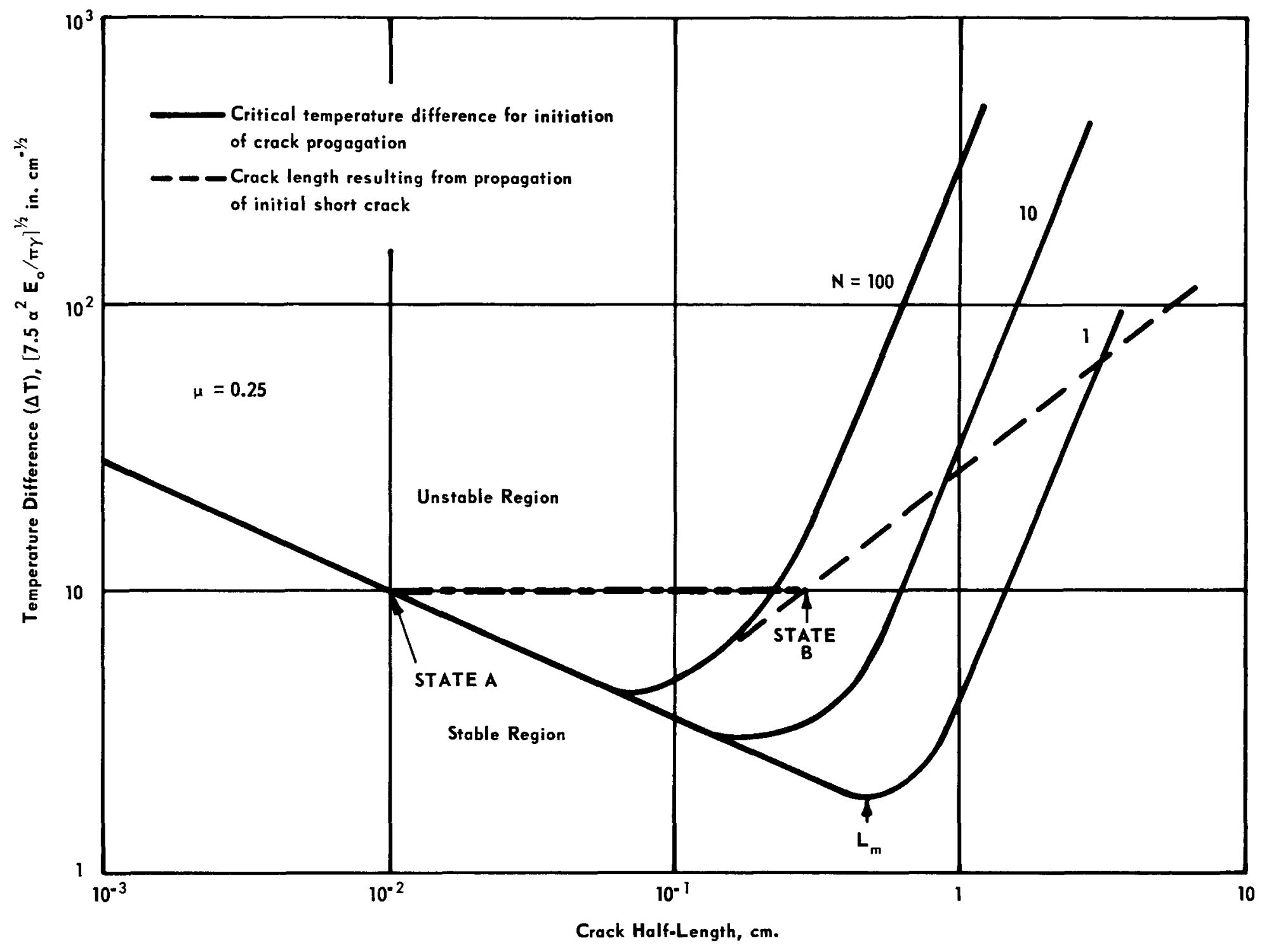


As an illustration, assume that the fuel exists in a crack state with $N=100$, denoted as state $A$ in Figure 3 , and that $\Delta T_{c}$ is attained. Kinetic crack propagation occurs because when $L<L_{m}$, i.e., the elastic energy release rate during crack propagation exceeds the surface fracture energy, this difference is converted into kinetic energy. The cracks continue to propagate until all of the kinetic energy and released strain energy are transformed into surface fracture energy. In the case of $N=100$, the crack length increases to state $B$, and the fuel becomes subcritical in $\Delta \mathrm{T}$ for further crack propagation. A further increase in $\Delta \mathrm{T}_{c}$ is required to initiate further crack propagation and strength loss as shown in Figure 2(a).

For short cracks of initial length ( $\left.L_{0}\right)$ and final length ( $\left.L_{f}\right)$ where $\mathrm{L}_{1} \gg \mathrm{L}_{0}$, the final crack length is given by:

$$
\mathrm{L}_{\mathcal{P}}=\left[3(1-2 \mu) / 8\left(1-\mu^{2}\right) \mathrm{L}_{0} \mathrm{~N}\right]^{1 / 2}
$$

Equation 33 shows that except for Poisson's ratio, the extent of crack propagation for a case where $L_{0} \ll L_{t}$ is independent of other material properties and dependent on 1 y upon crack density and the original crack size.

In fuel containing long initial cracks with $\mathrm{L}_{\circ}>\mathrm{L}_{m}$, thermal strain induces crack propagation that is quasi-stable and results in strength degradation as depicted in Figure $2(\mathrm{~b})$. This type of precracked brittle solid does not fail catastrophically in thermal shock. Thus a brittle solid with the correct crack length and crack density does not fail catastrophically in thermal shock. As discussed previously, this situation is favored by a low strength and a high elastic modulus plus a reasonably high crack density and a moderate initial crack length. The initial strength of the solid decreases with increasing Lo and there is little advantage in having $\mathrm{L}_{0} \gtrsim \mathrm{L}_{\mathrm{w}}$ due to the decrease in strength that occurs as Lo approaches the dimensions of the object itself.

The potential usefulness of these various thermal shock concepts as they apply to $\mathrm{PuO}_{2}$ spheres will now be examined with the objective of providing guidelines for handling ${ }^{2}{ }^{3} \mathrm{PuO}_{2}$ spheres during processing so as to minimize thermal shock damage or fracture.

\section{APPLICATION OF ANALYSES TO CERAMIC PPO SPHERES}

In order to apply the foregoing to ceramic $\mathrm{PuO}_{2.0}$ MHW spheres it is necessary either to have experimental values of the pertinent properties of the materials under the conditions of interest or to make estimates for them. Very few values for the high-temperature mechanical properties of $\mathrm{PuO}_{2.0}$, and essentially none for the mechanical properties of $\mathrm{PuO}_{2-x}$, are recorded in the literature. Application of the foregoing analysis to MHW spheres of porous $\mathrm{PuO}_{2.0}$ requires knowledge of the tensile fracture strength, Young's modulus, thermal expansion coefficient, Poisson's ratio, and total emissivity of theoretically dense $\mathrm{PuO}_{2.0}$, as well as the dependence of these properties on porosity, grain size, and temperature. Data for effective surface energy would also be very useful. Assumptions were necessary for essentially all of these properties of ceramic $\mathrm{PuO}_{2.0}$ where the models could be applied. An implicit assumption in these analyses is that the tensile strength of the ceramic is lower than the shear strength, and therefore, that a thermally shocked sphere will fail in tension. This has been demonstrated in numerous thermal fracture studies of other ceramic oxides and is considered a reasonable one in this case. 
The thermal expansion coefficient of polycrystalline $\mathrm{PuO}_{2.0}$ has been determined by several investigators and is the best known of all the properties required here. This property is essentially independent of porosity. The thermal conductivity and diffusivity of $82 \%$ dense PPO fuel was reported by Keenan, et a1.,10 and Lagedrost, et a1.11

The tensile strength of well-characterized $\mathrm{PuO}_{2.0}$ at room temperature or as a function of temperature is not known, but probably is very similar to that of $\mathrm{UO}_{2}$ and $\mathrm{ThO}_{2}$ at the same grain size and pore fraction. The stress to nucleate fracture in $\mathrm{PuO}_{2.0}$ is of the form:

$$
\mathrm{S}=\sigma_{0}+K D^{m}
$$

where,

$$
\begin{aligned}
S & =\text { stress to nucleate fracture } \\
\sigma_{0} & =\text { minimum tensile stress for dislocation motion in } \\
\text { the solid } & \\
D & =\text { average grain size in the polycrystalline fuel }
\end{aligned}
$$

and $K$ and $m$ are empirical constants.

The fracture strength is therefore higher for smaller grain sizes.

For $\mathrm{UO}_{2}$ at $25^{\circ} \mathrm{C}, \mathrm{m} \sim-0.12$, and at $1000^{\circ} \mathrm{C}, \mathrm{m} \simeq-0.84 .1^{3,14} \mathrm{~A} 1 \mathrm{so}$, reported values for the bend strength of high density $\mathrm{UO}_{2}$ with $\mathrm{D} \simeq 20 \mu \mathrm{m}$ at $25^{\circ} \mathrm{C}$ and $1000^{\circ} \mathrm{C}$ was 12,400 and $21,700 \mathrm{psi}$, respective1y. ${ }^{4}$ This indicates that the bend strength increases by a factor of about 1.8 in this temperature range. Measurements on porous $\mathrm{UO}_{2}$ with $\mathrm{D} \simeq 18 \mu \mathrm{m}$ indicate that, at a pore fraction $(P) \simeq 0.2$, the strength increase observed for this temperature increase was on1y about 1.12, with bend strengths of 9600 and 10,800 psi, respectively, at these temperatures. The bend strength of $\mathrm{ThO}_{2}$ with $\mathrm{P}=0.086$ and $\mathrm{D} \simeq 16.4 \mu \mathrm{m}$ was reported as $18,700 \mathrm{psi}$ at $25^{\circ} \mathrm{C} .15$ The bend strength of several single phase oxides has been shown to be about twice the tensile strength; ${ }^{16}$ the tensile strength of $\mathrm{PuO}_{2.0}$ applicab1e for insertion into the thermal stress expressions is therefore of the order of $10^{4}$ psi or 1 ess.

Due to present difficulty in defining the thermal boundary conditions pertinent to a PPO sphere while undergoing various thermal cycles during processing, the most logical approach at this point appears to be an evaluation of the thermal shock sensitivity via the various parameters discussed earlier and an identification of the most sensitive ones for $\mathrm{PuO}_{2.0}$. This would provide guidelines for protecting fabricated spheres from unnecessary thermal shock. However, in order to apply any of these analyses to $\mathrm{PuO}_{2.0}$ the requisite material properties at selected temperatures are required. Since several of these are not available, values for $\mathrm{ThO}_{2}$ and $\mathrm{UO}_{2}$ were used when available to obtain extrapolated values for $\mathrm{PuO}_{2.0}$.

Young's modulus for $\mathrm{PuO}_{2}$ with $\mathrm{P}$ (pore fraction) $=0.035$ at $25^{\circ} \mathrm{C}$ was obtained by extrapolating the experimental values ${ }^{17,18}$ for $\mathrm{UO}_{2}$ and $\mathrm{U}_{0.8} \mathrm{Pu}_{0.2} \mathrm{O}_{2.0}$ to $\mathrm{PuO}_{2.0}$ and assuming that the modulus varied 1 inearly with plutonium content as shown in Figure 4. For this value of $\mathrm{P}$ at $25^{\circ} \mathrm{C}$, $\mathrm{E}\left(\mathrm{PuO}_{2}\right)=23.3 \times 10^{6} \mathrm{psi}$. The modulus was also estimated at $\mathrm{P}=0.028$ from the published values ${ }^{17,19}$ for $\mathrm{ThO}_{2}$ and $\mathrm{UO}_{2}$ as shown in Figure 5; from 


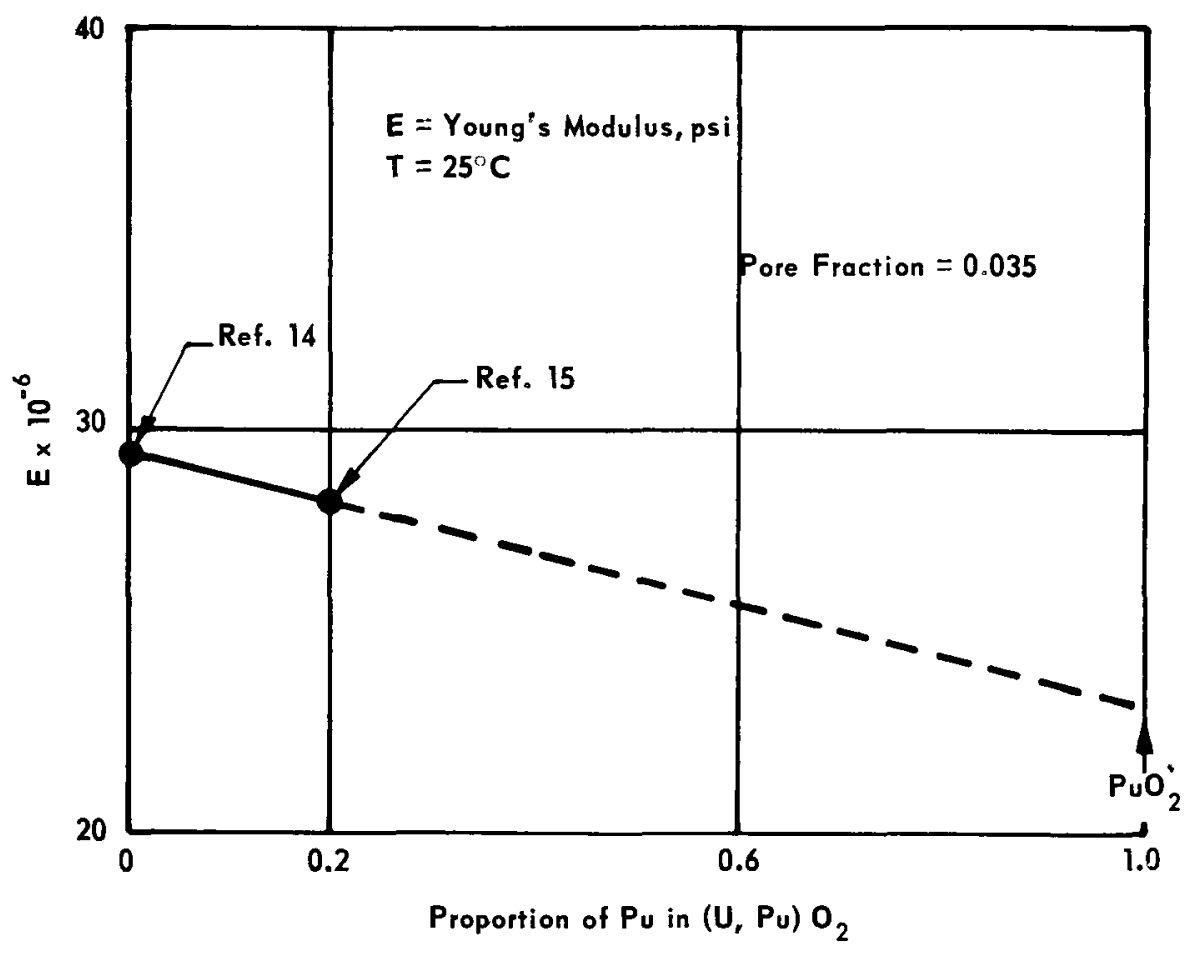

FIGURE 4 - Young's Modulus of $(U, P u) \mathrm{O}_{2}$.

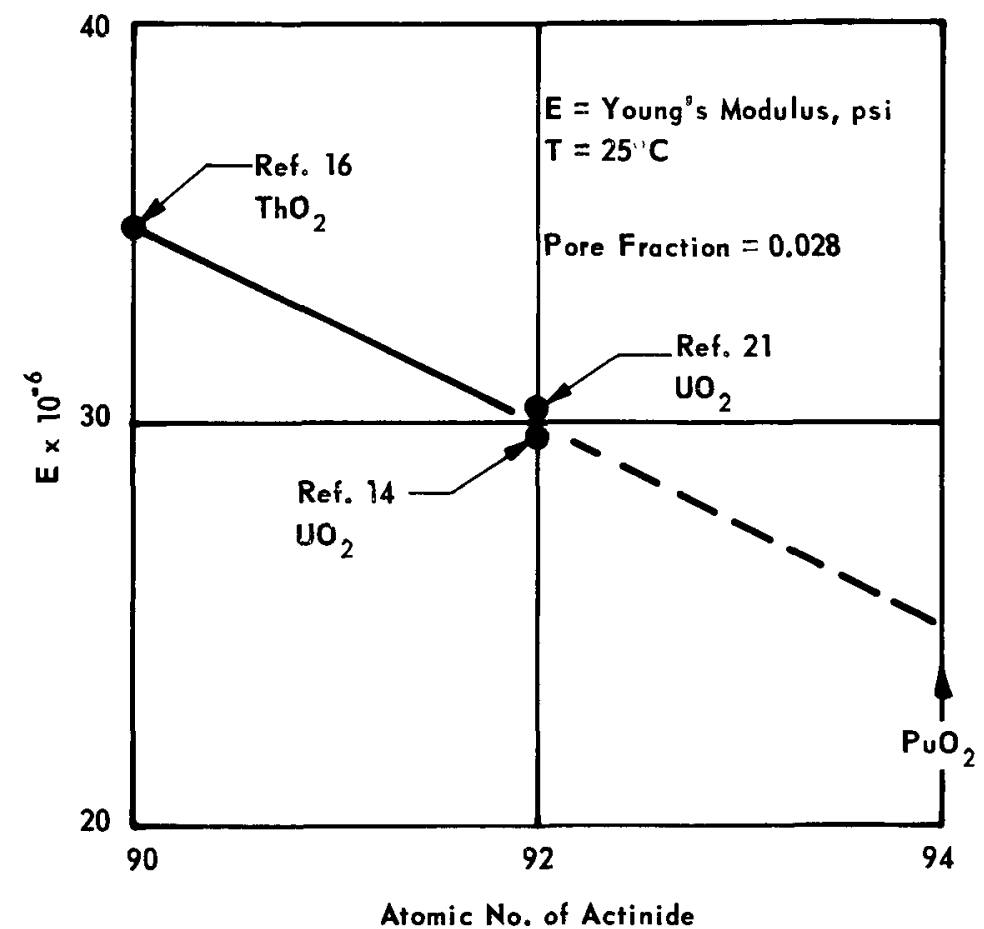

FIGURE 5 - Young's Modulus of actinide oxides. 
this procedure $E=25.0 \times 10^{6} \mathrm{psi}$. The porosity dependence of Young's modulus was estimated by extrapolating the porosity dependence of Young's modulus for $\mathrm{ThO}_{2}$ and $\mathrm{UO}_{2}$ to $\mathrm{PuO}_{2}$ as shown in Figure 6. From this extrapolation $\Delta \mathrm{E} / \Delta \mathrm{P} \simeq-4 \times 10^{7} \mathrm{psi} / \mathrm{P}$ for $\mathrm{PuO}_{2.0}$ at $25^{\circ} \mathrm{C}$. On this basis, the value of $E=25 \times 10^{6} \mathrm{psi}$ at $P=0.028$, calculates to $E \simeq 24.6 \times 10^{6} \mathrm{psi}$ at $P=0.035$. This is reasonably close to the value of $E=23.3 \times 10^{6}$ psi estimated from Figure 4 previously, thus giving confidence to the estimated value of the modulus for $\mathrm{PuO}_{2}$. The temperature dependence of Young's modulus was estimated from data for $\mathrm{ThO}_{2}^{20,21}$ and for $\mathrm{UO}_{2}{ }^{17,22}$ as shown in Figure 7. The value of $\Delta \mathrm{E} / \Delta \mathrm{T}$ for $\mathrm{PuO}_{2}$ is approximately $-4 \times 10^{3}$ psi $/{ }^{\circ} \mathrm{C}$ up to $\sim 1200^{\circ} \mathrm{C}$. At higher temperatures, the data for $\mathrm{UO}_{2}$ clearly show that these actinide oxides elastically soften and $E$ decreases as a complex function of temperature.

For MHW fuel of the current design, $P \simeq 0.15$. Using the assumptions outlined, the mechanical properties of $\mathrm{PuO}_{2}$ with $\mathrm{P}=0.15$ at various temperatures were estimated. For example, taking $\mathrm{E}=24 \times 10^{6} \mathrm{psi}$ at $25^{\circ} \mathrm{C}$ and $\mathrm{P}=0.035, \mathrm{E}$ at $1000^{\circ} \mathrm{C}$ was estimated as follows:

$$
\begin{aligned}
E & =E_{0}+(\mathrm{dE} / \mathrm{dP})(\Delta \mathrm{P})+(\mathrm{dE} / \mathrm{dT})(\Delta \mathrm{T}) \\
& \simeq 24 \times 10^{6}-4 \times 10^{7}(0.15-0.035)-4 \times 10^{3}\left(10^{3}\right) \\
& \simeq 24 \times 10^{6}-4.6 \times 10^{6}-4 \times 10^{6} \simeq 24 \times 10^{6}-8.6 \times 10^{6} \\
& \simeq 15.4 \times 10^{6} \mathrm{psi}
\end{aligned}
$$

Similarly, the elastic modulus at other temperatures of interest was calculated and the values are shown in Table 2 . The value of the tensile strength of PPO fuel at temperatures up to $1200^{\circ} \mathrm{C}$ is difficult to estimate, but it probab1y lies somewhere between 2000 and 10,000 psi. Thermal shock estimates are, therefore, made in this strength range.

The thermal conductivity values for theoretically dense $\mathrm{ThO}_{2}{ }^{23}$ and for $\mathrm{UO}_{2}{ }^{24}$ were compared with data for $\mathrm{PuO}_{2}{ }_{1,25}$, in order to assess thermal conductivity variations in these actinide oxides. At $1000^{\circ} \mathrm{C}, k$ values for dense $\mathrm{ThO}_{2}$ and $\mathrm{UO}_{2}$ were essentially identical at $7 \times 10^{-3} \mathrm{cal} / \mathrm{cm}-$ sec- ${ }^{\circ} \mathrm{C}$. Reported for $\mathrm{PuO}_{2}$ were $k$ values of $7 \times 10^{-3} \mathrm{cal} / \mathrm{cm}-\mathrm{sec}-{ }^{\circ} \mathrm{C}$,

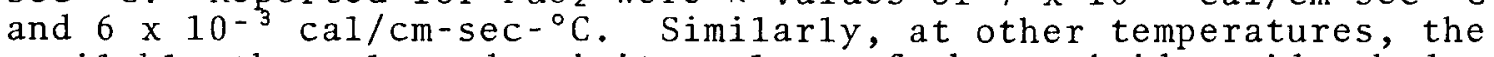
available thermal conductivity values of the actinide oxides had comparable values. The values at a given temperature are similar enough to provide confidence in the available thermal conductivities for $\mathrm{PuO}_{2}$ having reasonably homogeneous microstructures. Recent microscopic evidence for MHW fuel spheres indicates that some microstructural heterogeneity exists in the present spherical fuel form between the pole and equator. ${ }^{26}$ These heterogeneities will cause variations in the thermal conductivity, resulting in some deviation of the heat flow in an actual sphere from that assumed here. Quantitative estimates of these possible variations are not presently available.

The simplest functional dependence between thermal conductivity and porosity for solids having primarily a phonon heat transfer mechanism is given by:

$$
K_{p_{s}}=K_{s}(1-P)
$$




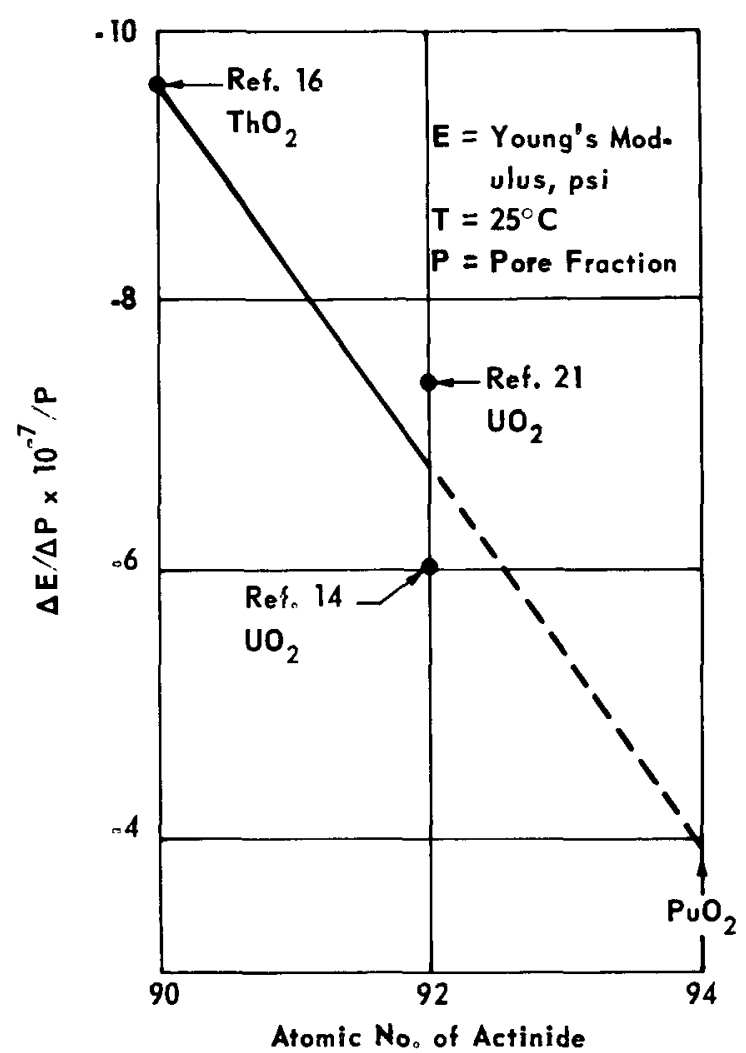

FIGURE 6 - Variation of Young's Moduzus with pore fraction in actinide oxides.

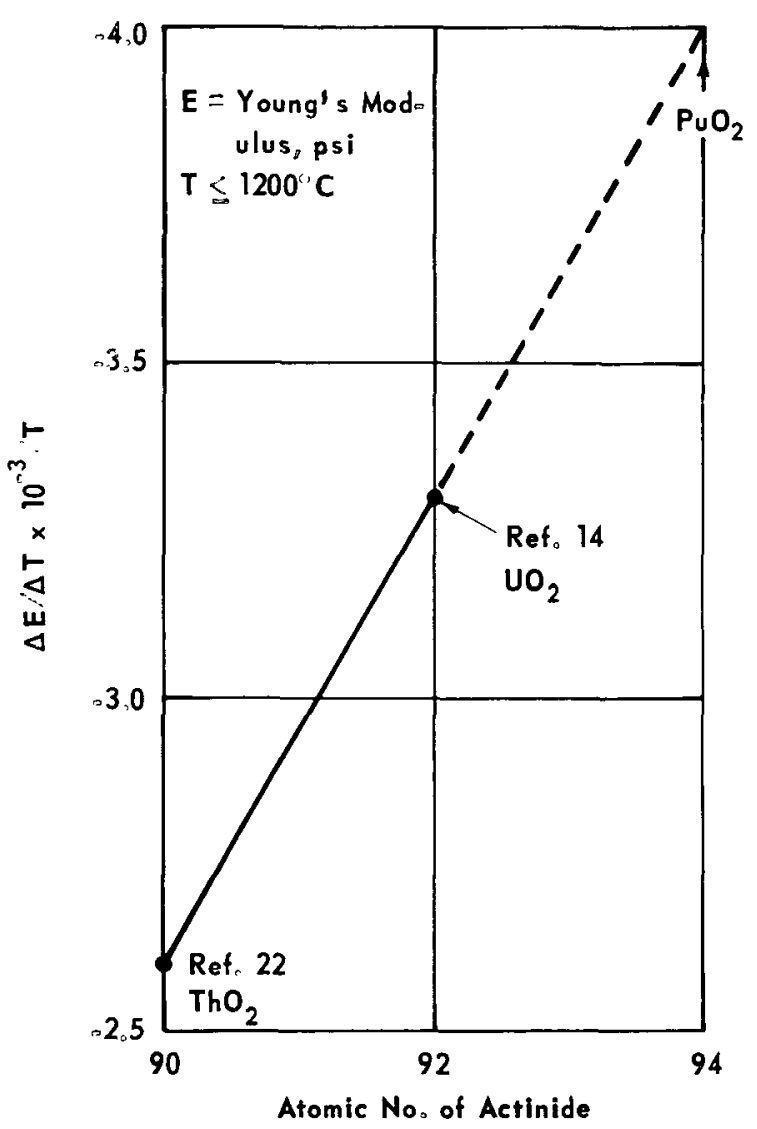

FIGURE 7 - Variation of Young's Modulus with temperature in actinide oxides.

\section{aetinide oxides.}


where,

$$
\begin{aligned}
K_{P_{s}} & =\text { thermal conductivity of porous solid } \\
K_{s} & =\text { thermal conductivity of theoretically dense solid } \\
P & =\text { pore fraction. }
\end{aligned}
$$

\begin{tabular}{|c|c|c|c|}
\hline \multirow[b]{2}{*}{$\begin{array}{l}\text { Temperature } \\
\left({ }^{\circ} \mathrm{C}\right)\end{array}$} & $P=0.18$ & \multicolumn{2}{|c|}{$\mathrm{P}=0.15$} \\
\hline & $\begin{array}{c}\kappa \times 10^{3} \\
\left(\mathrm{cal} / \mathrm{cm}-\mathrm{sec}^{\circ}{ }^{\circ} \mathrm{C}\right) \\
\end{array}$ & $\begin{array}{c}\mathrm{k} \times 10^{3} \\
\left(\mathrm{cal} / \mathrm{cm}-\mathrm{sec}^{\circ} \mathrm{C}\right) \\
\end{array}$ & $\begin{array}{l}\mathrm{E} \times 10^{6} \\
(\mathrm{psi}) \\
\end{array}$ \\
\hline 400 & 9.1 & 11.1 & 17.8 \\
\hline 600 & 6.9 & 9.1 & 17.0 \\
\hline 800 & 5.6 & 6.7 & 16.2 \\
\hline 1000 & 4.9 & 6.1 & 15.4 \\
\hline 1200 & 4.4 & 5.3 & 14.6 \\
\hline
\end{tabular}

Table 2

THERMAL CONDUCTIVITY ( $k$ ) AND ELASTIC MODULUS (E) FOR POROUS PuO

This expression has been found to apply for several oxides at $\mathrm{p}$ values below 0.1 and is reasonably applicable at $P=0.15$, the case of interest for MHW fuel. In the following, it is assumed that Equation 35 adequately accounts for the presence of porosity in the $\mathrm{PuO}_{2}$ fuel. The thermal conductivity values available from the two known references ${ }^{1 *}, 25$ are given for various temperatures of interest in Table 2. The values are in sufficient agreement for use in the thermal shock calculations.

The thermal diffusivity of $\mathrm{PuO}_{2}$ with a pore fraction, $\mathrm{P}=0.15$ was estimated from earlier data ${ }^{25}$ and compared with other published values.10,11 These values are listed for various temperatures in Table 3 . The available diffusivity values for porous $\mathrm{PuO}_{2}$ show good agreement and these values are used in the following analyses.

Using the properties of $\mathrm{PuO}_{2}$ with a pore fraction of 0.15 , the thermal conditions which cause thermal shock fracture of MHW fuel spheres were calculated. Examples are given and the maximum acceptable heating and cooling rates at three strength leve1s, using the more conservative Equations $14 \mathrm{a}$ and $15 \mathrm{a}$, are shown in Figure 8 as a function of average sphere temperature.

*Data in this Mound Laboratory compilation originally from R. L. Gibby, Quarterly Progress Report, Jan-March, 1966, Reactor Fue1s and Materia1s Development Program, BNWL-CC-694, Battelle Northwest, Richfield, Washington (May 1966) p. 3.5. 


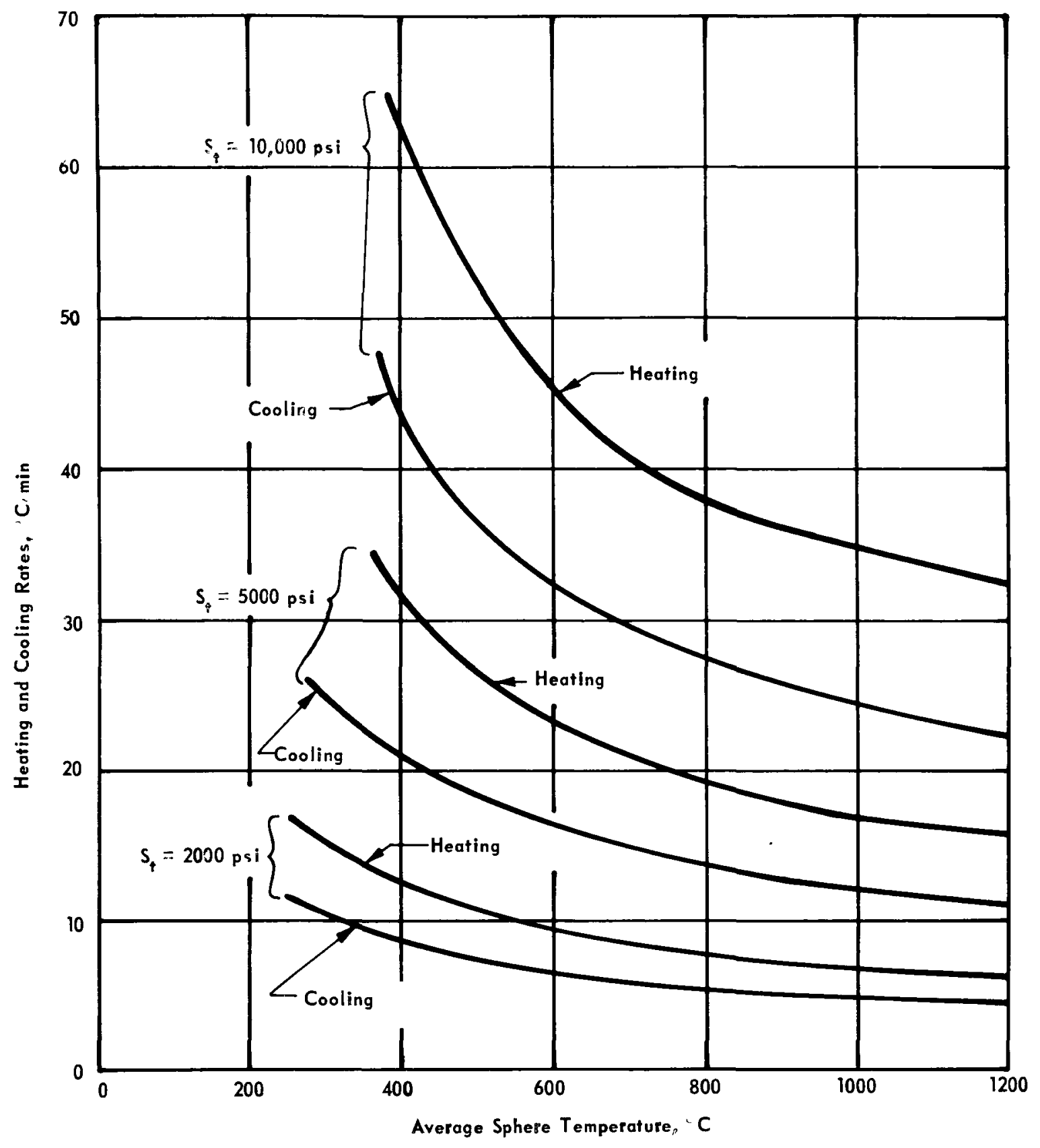

FIGURE 8 - Maximum linear heating and cooling rates for MHW sphere. 
Table 3

THERMAL DIFFUSIVITY OF POROUS $\mathrm{PuO}_{2}$

\begin{tabular}{|c|c|c|}
\hline $\begin{array}{l}\text { Temperature } \\
\left({ }^{\circ} \mathrm{C}\right)\end{array}$ & $\frac{P=0.18}{a x 10^{2}}$ & $\begin{array}{l}\mathrm{P}=0.15 \\
\mathrm{a} \times 10^{2} \\
\left(\mathrm{~cm}^{2} / \mathrm{sec}\right)\end{array}$ \\
\hline 400 & 1.4 & 1.4 \\
\hline 600 & 1.1 & 1.1 \\
\hline 800 & 0.8 & 0.85 \\
\hline 1000 & 0.7 & 0.70 \\
\hline 1200 & 0.6 & 0.61 \\
\hline
\end{tabular}

Constant Rate of Heating or Cooling of the Surface of a Sphere

For Cooling:

$$
Q_{\max }=\frac{\operatorname{aSt}(1-\mu)}{E \alpha} \cdot \frac{5}{r_{m}^{2}}
$$

and

$$
Q_{\max }=\frac{\operatorname{aSt}(1-\mu)}{E \alpha} \cdot \frac{10}{r_{m}^{2}}
$$

$\mathrm{T}=400^{\circ} \mathrm{C}$

If $S_{t}=2000 \mathrm{psi}$,

$$
\begin{aligned}
Q_{\max } & =\frac{1.4 \times 10^{-2} \times 2 \times 10^{3} \times 0.7}{17.8 \times 10^{6} \times 11 \times 10^{-6}} \cdot \frac{5}{(1.86)^{2}} \\
& =0.15^{\circ} \mathrm{C} / \mathrm{sec}=8 .{ }^{\circ} \mathrm{C} / \mathrm{min} \text { using }(14 \mathrm{a})
\end{aligned}
$$

or, $Q_{\max }=17.4{ }^{\circ} \mathrm{C} / \mathrm{min}$ using (14).

If $\mathrm{S}_{\mathrm{t}}=10,000 \mathrm{psi}$,

$$
\begin{aligned}
& Q_{\max }=43.5^{\circ} \mathrm{C} / \mathrm{min} \text { using }(14 \mathrm{a}) \\
& \text { or, }=87^{\circ} \mathrm{C} / \mathrm{min} \text { using }(14) .
\end{aligned}
$$

$\mathrm{T}=800^{\circ} \mathrm{C}$

If $S_{t}=2000$ psi,

$$
\begin{aligned}
& Q_{\text {max }}=0.09^{\circ} \mathrm{C} / \mathrm{sec}=5.5^{\circ} \mathrm{C} / \mathrm{min} \text { using }(14 \mathrm{a}) \\
& \text { or },=11.0^{\circ} \mathrm{C} / \mathrm{min} \text { using }(14)
\end{aligned}
$$


If $\mathrm{S}_{\mathrm{t}}=10,000 \mathrm{psi}$,

$$
\begin{aligned}
\mathrm{Q}_{\text {max }} & =27.5^{\circ} \mathrm{C} / \mathrm{min} \text { using }(14 \mathrm{a}) \\
\text { or, } & =55^{\circ} \mathrm{C} / \mathrm{min} \text { using }(14)
\end{aligned}
$$

$\mathrm{T}=1200^{\circ} \mathrm{C}$

$$
\begin{aligned}
& \text { If } \mathrm{S}_{t}=2000 \mathrm{psi}, \\
& \mathrm{Qmax}_{\text {max }}=0.076^{\circ} \mathrm{C} / \mathrm{sec}=4.5^{\circ} \mathrm{C} / \mathrm{min} \text { using }(14 \mathrm{a}) \\
& \text { or, }=9^{\circ} \mathrm{C} / \mathrm{min} \text { using }(14) . \\
& \text { If } \mathrm{S}_{t}=10,000 \mathrm{psi}, \\
& Q_{\text {max }}=22.5^{\circ} \mathrm{C} / \mathrm{min} \text { using }(14 \mathrm{a}) \\
& \text { or },=45^{\circ} \mathrm{C} / \mathrm{min} \text { using }(14) .
\end{aligned}
$$

These results clearly indicate that acceptable cooling rates for MHW spheres increase as the mean temperature of the sphere decreases, assuming the tensile strength of the fuel is reasonably independent of temperature over the temperature range of 400 to $1200^{\circ} \mathrm{C}$.

For heating:

$$
\begin{aligned}
& Q_{\max }=\frac{a S_{t}(1-\mu)}{E \alpha} \cdot \frac{15}{r_{m}^{2}} \\
& Q_{\max } \simeq \frac{a S_{t}(1-\mu)}{E \alpha} \cdot \frac{7}{r_{m}^{2}}
\end{aligned}
$$

$\mathrm{T}=400^{\circ} \mathrm{C}$

If $S_{t}=2000 \mathrm{psi}$,

$$
\begin{aligned}
Q_{\max } & =\frac{1.4 \times 10^{-2} \times 2 \times 10^{3} \times 0.7}{17.8 \times 10^{6} \times 11 \times 10^{-6}} \cdot \frac{7}{(1.86)^{2}} \\
& =0.21{ }^{\circ} \mathrm{C} / \mathrm{sec}=12.6{ }^{\circ} \mathrm{C} / \mathrm{min} \text { using }(15 \mathrm{a})
\end{aligned}
$$

or $\mathrm{Q}_{\max }=27.0{ }^{\circ} \mathrm{C} / \mathrm{min}$ using (15).

If $\mathrm{S}_{\mathrm{t}}=10,000 \mathrm{psi}$,

$$
\mathrm{Q}_{\text {max }}=63^{\circ} \mathrm{C} / \mathrm{min} \text { using }(15 \mathrm{a})
$$

or, $\mathrm{Q}_{\text {max }}=135^{\circ} \mathrm{C} / \mathrm{min}$ using (15)

$\mathrm{T}=800^{\circ} \mathrm{C}$

If $\mathrm{S}_{\mathrm{t}}=2000 \mathrm{psi}$,

$$
\begin{aligned}
Q_{\max } & =\frac{0.8 \times 10^{-2} \times 2 \times 10^{3} \times 0.7}{16.2 \times 10^{6} \times 11 \times 10^{-6}} \cdot \frac{7}{(1.86)^{2}} \\
& =0.13^{\circ} \mathrm{C} / \mathrm{sec}=7.6{ }^{\circ} \mathrm{C} / \text { min using }(15 \mathrm{a})
\end{aligned}
$$




$$
\text { or } Q_{\text {max }}=16.3^{\circ} \mathrm{C} / \mathrm{min} \text { using }(15)
$$

If $\mathrm{S}_{\mathrm{t}}=10,000 \mathrm{psi}$,

$$
Q_{\text {max }}=38^{\circ} \mathrm{C} / \mathrm{min} \text { using }(15 \mathrm{a})
$$

or, $\mathrm{Qmax}_{\mathrm{ma}}=81.5^{\circ} \mathrm{C} / \mathrm{min}$ using (15)

$\mathrm{T}=1200^{\circ} \mathrm{C}$

If $\mathrm{S}_{\mathrm{t}}=2000 \mathrm{psi}$

$$
\begin{aligned}
& Q_{\max }=\frac{0.61 \times 10^{-2} \times 2 \times 10^{3} \times 0.7}{16.6 \times 10^{6} \times 11 \times 10^{-6}} \cdot \frac{7}{(1.86)^{2}} \\
&=0.12^{\circ} \mathrm{C} / \mathrm{sec}=6.5^{\circ} \mathrm{C} / \mathrm{min} \text { using }(15) \\
& \text { or, } Q_{\max }=13.8^{\circ} \mathrm{C} / \mathrm{min} \text { using }(15 \mathrm{a}) \\
& \text { If } \mathrm{S}_{t}=10,000 \mathrm{psi}, \\
& \mathrm{Q}_{\mathrm{max}}=32.5^{\circ} \mathrm{C} / \mathrm{min} \text { using }(15) \\
& \text { or, } \mathrm{Q}_{\max }=69^{\circ} \mathrm{C} / \mathrm{min} \text { using }(15 \mathrm{a})
\end{aligned}
$$

Cooling or Heating a Sphere with a Constant Biot's Modulus

As discussed previously, Biot's modulus for a sphere is given by $\beta=\mathrm{rh} / \mathrm{k}$. In order to compute the critical temperature difference which causes the sphere to fracture, it is necessary to have the value of the surface heat transfer coefficient, $h$. The $h$ values for alumina spheres in air and fused salt have been determined at various temperatures. ${ }^{6}$ The values for air were assumed to be appropriate for MHW spheres in a helium atmosphere and this assumption seems reasonable for the present case.

These values and the computed $B$ values for porous $\mathrm{PuO}_{2}$ at various temperatures are shown in Table 4 . The results of calculations, using Equation 16 for the critical temperature change that causes the sphere to fracture, are shown in Figure 9 for assumed tensile strength values of 2000,5000 and 10,000 psi.

Table 4

BIOT'S MODULUS ( $\beta$ ) AND SURFACE HEAT TRANSFER COEFFICIENT (h)
FOR PuO $\mathrm{PuO}_{2}$ SPHERES IN AIR

$\begin{array}{ccc}\begin{array}{c}\text { Temperature } \\ \left({ }^{\circ} \mathrm{C}\right)\end{array} & \begin{array}{c}\mathrm{h} \times 10^{3} \\ \left(\mathrm{cal} / \mathrm{sec}-{ }^{\circ} \mathrm{C}-\mathrm{cm}\right)\end{array} & \frac{\beta}{\text { (dimensionless) }} \\ 440 & 2.8 & 0.60 \\ 800 & 3.6 & 1.2 \\ 1200 & 6.8 & 2.9\end{array}$




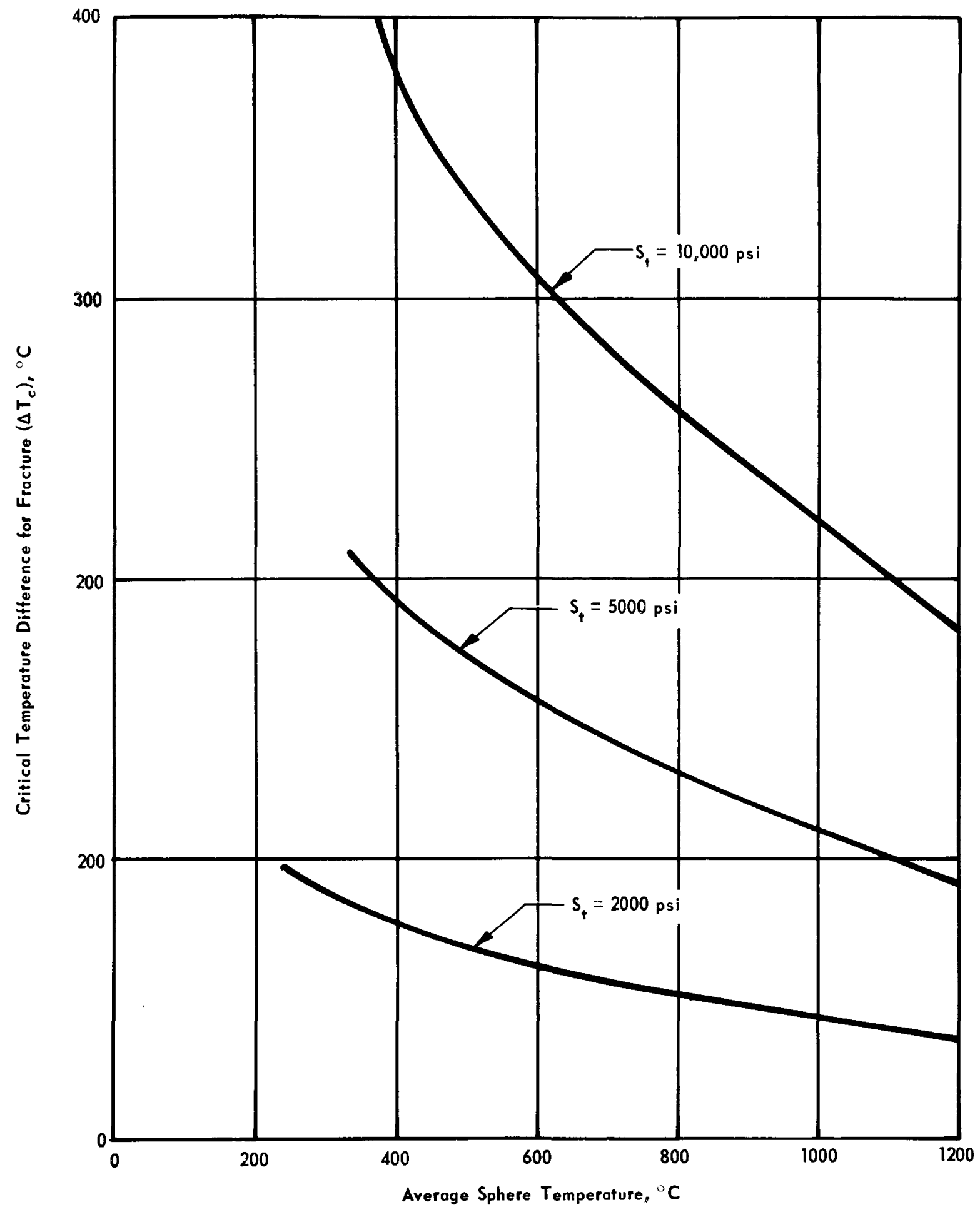

FIGURE 9 - Critical temperature difference for MHW sphere fracture. 
Recently measured temperature gradient measurements in a 100 -watt MHW sphere reported by LASL $^{27}$ indicate that the existing gradient in one of these spheres in a relatively low-flow argon atmosphere is approximately of the order indicated in Figure 9 for $S_{t}=5000$ psi. The sphere was externally heated by a tube furnace while in the gas atmosphere. The heat transfer conditions for a self-heating sphere in a gaseous atmosphere are not the same as those used in deriving Equation 16, but the results will be indicative of the temperature change a sphere can sustain. Solutions for the stress field in a self-heating sphere and with prescribed surface heat transfer conditions could not be found in the literature. While Equation 16 is the solution for a sphere initially at a uniform temperature, the results shown in Figure 9 should be reasonable first approximations of the thermal shock conditions necessary to fracture a self-heating sphere. The tensile fracture strength of the fuel is obviously a critical property and is presently unknown for this ceramic material. A relatively modest increase in the tensile strength of the fuel results in a considerable improvement in the thermal shock fracture resistance of the fuel sphere.

The time required for a PPO sphere to reach the critical fracture stress after a temperature change, $\Delta \mathrm{T}_{\mathrm{c}}$, is imposed upon the sphere is obtained from Equation 19. Values for $\theta$ from Figure 1--values at $r=$ a for application of cooling shocks, and values at $r=0$ for heating shocks-were used to compute the time to fracture for porous $\mathrm{PuO}_{2}$. These results are shown in Figure 10. The time required to reach the fracture stress after the application of $\Delta \mathrm{T}_{c}$ is considerably longer when the temperature change is positive, i.e., a heating, rather than a cooling, shock.

\section{Thermal Fracture by Radiation Cooling or Heating}

Using Equation 23 and assuming a total emissivity of 0.8 for the fuel, the radiation temperature change required to fracture a porous $\mathrm{PuO}_{2}$ sphere by heating or cooling was calculated and is shown in Figure 11 for three strength levels. Figure 11 indicates that relatively severe changes in the radiation environment of a MHW sphere are required to induce fracture. For instance, a sphere at $1000^{\circ} \mathrm{C}$ with a strength of $2000 \mathrm{psi}$ which is suddenly placed in a new radiation environment at $450^{\circ} \mathrm{C}$ or $1450^{\circ} \mathrm{C}$ would fracture by thermal shock. Reasonable precautions in controlling the thermal radiation environment of the fuel spheres should preclude thermal shock fracture by this mechanism.

Therma1 Stress Damage by Radiation Cooling or Heating

In order to minimize thermal stress damage effects in PPo spheres it is important to maximize, if possible, $S_{t}^{*}$ in Equation 28 for a sphere. This can be accomplished in a real material by varying the radius of the sphere, increasing the number $N$ of crack initiation sites, or increasing $\gamma_{e} f$, the effective fracture surface energy. As $r$ increases, $S_{t}^{2}$ (optimum) decreases; thus, for large spheres, strength is optimum at a lower value than for small spheres. Since $r$ is fixed in the case of the MHW generator by the system design, the only quantities in Equation 28 which can be controlled are $\gamma_{e f t}, N$, and the crack length, Lo. Experimental data are scarce for $\gamma_{e f}$ as a function of the microstructure of various ceramics, but there is evidence that $\gamma_{e \neq p}$ of ceramic $\mathrm{Al}_{2} \mathrm{O}_{3}$ can be increased to approximately $10^{8} \mathrm{ergs} / \mathrm{cm}^{2}$ from approximately $10^{4} \mathrm{ergs} / \mathrm{cm}^{2}$ by the introduction of short molybdenum fibers into the ceramic. If the thermal damage or fracture resistance of PPO spheres becomes a serious problem, the introduction of inert metal fibers into the ceramic would be an 


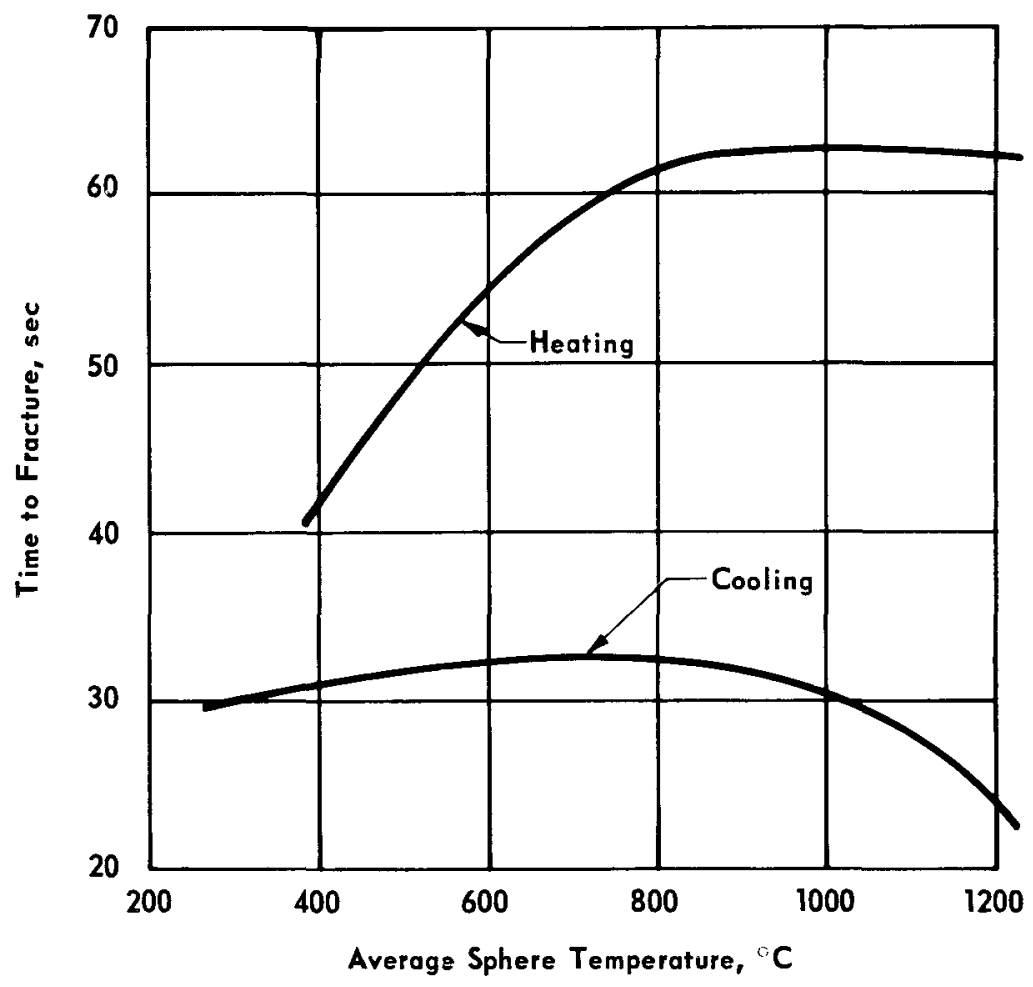

FIGURE 10 - Fracture time for MHW sphere.

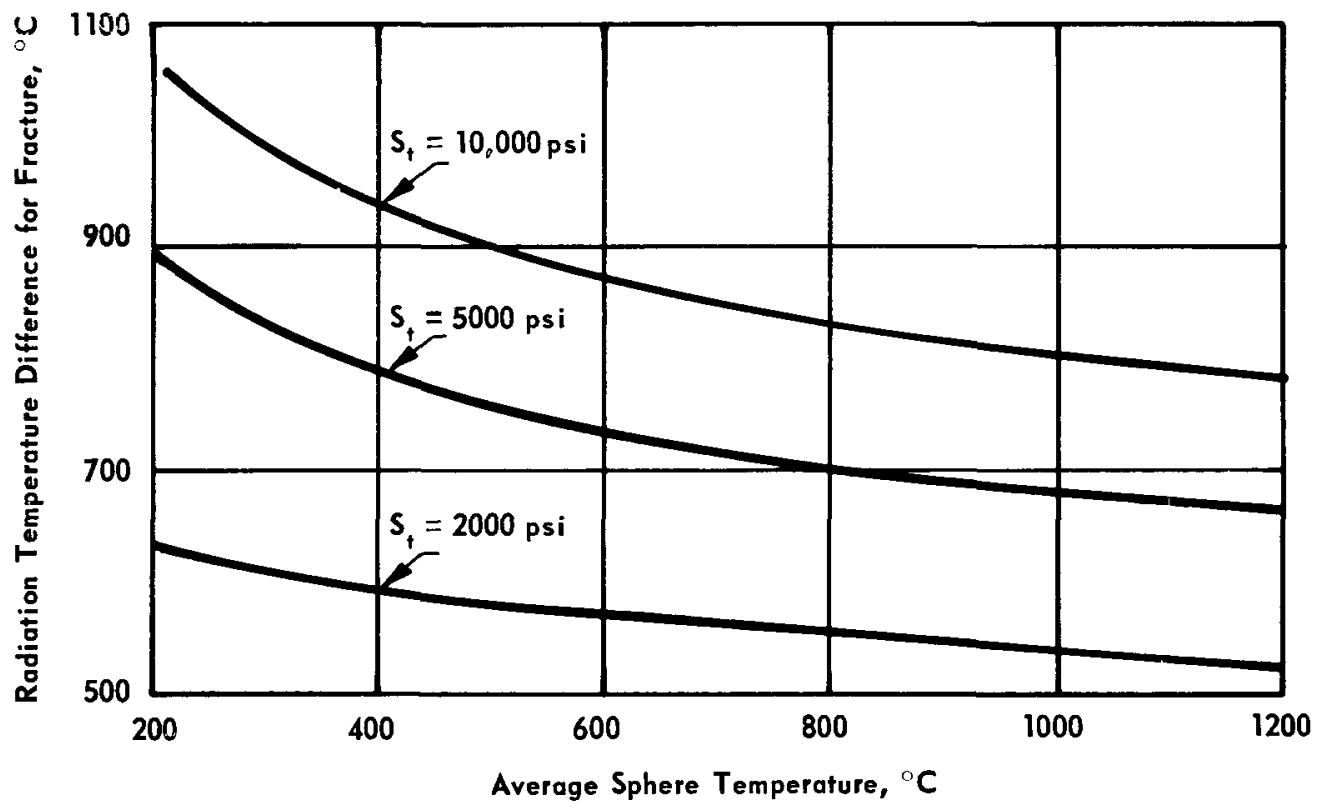

FIGURE 11 - Radiation temperature thermal shock for fracture of MHW sphere. 
effective way to improve these properties. This is based upon the assumption that the oxide effectively bonds to the metal fibers during fabrication, so that the bonding between the two will increase "effective $\gamma$ ". Also, proper manipulation of the microstructure increases $N$ during thermal fracturing, and thereby increases the thermal damage resistance.

Due to the difficulty in assessing the thermal boundary conditions of a PPO sphere during processing, it is not a simple matter to specify which of the thermal shock models are most pertinent. A conservative view would require that al1 be employed and the one providing minimum $\Delta T$ required for sphere fracture be analyzed carefully in a particular situation. As shown by the PPO fuel behavior in Figure 2(a), a thermal shock insufficient for catastrophic failure, nevertheless results in a critical $\Delta \mathrm{T}_{c}$, significantly weakening the fuel without any visible evidence. Subsequent handling and thermal cycling of the sphere can then lead to stresses exceeding the new, lower $S_{t}$ value, and the sphere may fracture for no apparent reason.

At temperatures above $\sim 1350^{\circ} \mathrm{C}$, considerable creep probably occurs in the fuel due to thermally induced stresses. As the rate of creep increases, there is a point at which the sphere becomes fairly resistant to thermal shock fracturing. This occurs because creep relieves stress before the critical fracture stress is achieved in a given thermal shock situation. Estimates of these effects could be made if very high temperature thermal shock were anticipated for the fuel spheres.

\section{SUMMARY}

Using a conservative stress analysis for the sphere, the maximum allowable heating rate for the surface varies from $35^{\circ} \mathrm{C} / \mathrm{min}$ to $7^{\circ} \mathrm{C} / \mathrm{min}$ at $1000^{\circ} \mathrm{C}$, as $S_{t}$ varies from $10^{4}$ to $2 \times 10^{3}$ psi. Maximum allowable cooling rates for the sphere surface vary from about $25^{\circ} \mathrm{C} / \mathrm{min}$ to $5^{\circ} \mathrm{C} / \mathrm{min}$ as the strength varies over this same range. For a constant strength, higher heating and cooling rates can be tolerated by a sphere at lower temperatures.

With a constant heat transfer coefficient, the maximum thermal shock that a sphere can withstand is larger at lower temperatures and is directly proportional to the tensile fracture strength of the fue 1 . The critical $\Delta \mathrm{T}_{\mathrm{c}}$ for fracture under these conditions varies from about $220^{\circ} \mathrm{C}$ to $450^{\circ} \mathrm{C}$, as $\mathrm{S}_{t}$ varies from $10^{4}$ to $2 \times 10^{3} \mathrm{psi}$ at $1000^{\circ} \mathrm{C}$. Using heat transfer coefficients applicable for a sphere in air, $\Delta \mathrm{T}$ e increases at lower temperatures, and thus, a sphere is more shock fracture resistant at lower temperatures.

Relatively severe radiation heating and cooling shocks are required to fracture the fuel sphere. Radiation thermal shocks of $810^{\circ} \mathrm{K}$ to $540^{\circ} \mathrm{K}$ are required to cause sphere fracture as $S_{t}$ varies from $10^{4}$ to $2 \times 10^{3}$ psi. Thermal stress damage resistance of a sphere can be increased by 1 ) increasing the surface fracture energy of the fuel, 2) increasing the number and size of initial cracks present in the fue1, or 3) decreasing the sphere radius. The surface fracture energy of the fuel can be effectively increased by placing short, unoriented refractory metal wires in the fue 1 , provided that good bonding is achieved between the fuel and wires during fuel fabrication. The number and size of initial cracks can be increased by producing large-grained microstructures and high porosity in the fuel. 
REFERENCES

1. W. D. Kingery, J. Amer. Ceram. Soc., 38:1, 3 (1955).

2. R. L. Coble and W. D. Kingery, J. Amer. Ceram. Soc., 38:1, 33 (1955).

3. D. P. H. Hasse1man, J. Amer. Ceram. Soc., 46:11, 535 (1963).

4. D. P. H. Hasse1man, J. Amer. Ceram. Soc., 52:11, 600 (1969).

5. J. Nakayama and M. Ishizuka, Bu11. Amer. Ceram. Soc., 45:7, 666 (1966).

6. W. B. Cranda11 and J. Ging, J. Amer. Ceram. Soc., 38:1, 44 (1955).

7. D. P. H. Hasselman and W. B. Crandall, J. Amer. Ceram. Soc., 46:9, 434 (1963).

8. D. P. H. Hasselman, J. Amer. Ceram. Soc., 46:5, 229 (1963).

9. D. P. Hasse1man, in Ceramics in Severe Environments, Vo1. 5 of Materials Science Research, W. Kriegel and H. Palmour III (ed.), Plenum Press, New York, 1971, pp. 89-103.

10. T. K. Keenan et al., Data Sheets for PPO Radioisotopic Fue1, LA5160-MS, Los Alamos Scientific Laboratory, Los Alamos, N. Mex. (February 1973), 11 pp.

11. J. F. Lagedrost et al., Nucl. Appl., 4:1, 54 (1968).

12. S. M. Wiederhorn, in Mechanical and Thermal Properties of Ceramics, J. B. Wachtman, Jr. (ed.), Special Publication 303, National Bureau of Standards, Washington, D.C., 1969, pp. 217-241.

13. J. F. Lynch, C. G. Ruderer, and W. H. Duckworth (ed.), Engineering Properties of Selected Materials, American Ceramic Society, Columbus, ohio, 1966, p. 9.5.4.10-6.

14. F. P. Knudsen, H. S. Parker, and M. D. Burdick, J. Amer. Ceram. Soc., 43:12, $641(1960)$.

15. F. P. Knudsen, J. Amer. Ceram. Soc., 42:8, 376 (1959) .

16. S. S. Manson and R. W. Smith, J. Amer. Ceram. Soc., 38:1, 18 (1955). 
17. M. O. Marlowe and A. I. Kaznoff, in Ceramic Nuclear Fuels, 0. L. Kruger and A. I. Kaznoff (ed.), American Ceramic Society, Columbus, Ohio, 1969, pp. 90-99.

18. A. W. Nutt, Jr., A. W. Allen, and J. H. Handwerk, J. Amer. Ceram. Soc., 53:4, $205(1970)$.

19. S. Spinner, F. P. Knudsen, and L. Stone, J. Res. Nat. Bur. Stand., Sect. C, 67C:1, 39 (1963).

20. S. M. Lang and E. P. Knudsen, J.Amer. Ceram. Soc., 39:12, 415 $(1956)$.

21. J. B. Wachtman, Jr., in Mechanical and Thermal Properties of Ceramics, J. B. Wachtman, Jr. (ed.), Pub1ication 303, Nationa1 Bureau of Standards, Washington, D.C., 1969, pp. 139-168.

22. R. J. Forlano, A. W. Allen, and R. J. Beals, J.Amer. Ceram. Soc., $\underline{50: 2}, 93(1967)$.

23. D. R. Flynn, in Mechanical and Therma1 Properties of Ceramics, J. B. Wachtman, Jr. (ed.), Special Publication 303, National Bureau of Standards, Washington, D.C., 1969, pp. 63-123.

24. T. G. Godfrey et a1., Therma1 Conductivity of Uranium Dioxide and Armco Iron by an Improved Radial Heat Flow Technique, ORNL-3556, Oak Ridge National Laboratory, Oak Ridge, Tenn. (June 1964), 72 pp.

25. W. H. Smith, D. R. Rogers, and G. L. Silver, Plutonium-238 Isotopic Fuel Form Data Sheets, MLM-1691 (Oct. 31, 1969), p. 45 .

26. R. E. Zielinski and R. R. Jaeger, Mound Laboratory, private communication.

27. T. K. Keenan and R. A. Kent, Los Alamos Scientific Laboratory, private communication. 